\section{Configuration Management}

PHASE II

\section{IMPLEMENTATION GUIDANCE}

March 1994

Lesued By:

Configuration Management Working Group

MARTIN MARIETTA ENERGY SYSTEMS, INIC. Oak Ridge, Tennessee

MANAGED BY

MARTIN MARIETTA ENERGY SYSTEMS, INC.

FOR THE UNITED STATES

DEPARTMENT OF ENERGY

DIGTFIBUTION OF THIS DOCUMENT IS UNLMMITED 
This report has been reproduced directly from the best avallable copy.

Avallable to DOE and DOE contractors from the Omce of Scientific and Technical Information, P.O. Box 62, Oak Ridge, TN 37831; prices available from (615) 576-8401.

Avallable to the public from the National Technical Information Service, U.S. Department of Commerce, 5285 Port Royal Rd., Springneld, VA 22161.

\section{DISCLAIMER}

This report was prepared as an account of work sponsored by an agency of the United States Government. Neither the United States Government nor any agency thereof, nor any of their employees, makes any warranty, express or implied, or assumes any legal liability or responsibility for the accuracy, completeness, or usefulness of any information, apparatus, product, or process disclosed, or represents that its use would not infringe privately owned rights. Reference herein to any specific commercial product, process, or service by trade name, trademark, manufacturer, or otherwise, does not necessarily constitute or imply its endorsement, recommendation, or favoring by the United States Government or any agency thereof. The views and opinions of authors expressed herein do not necessarily state or reflect those of the United States Government or any agency thereof. 


\section{Configuration Management}

\section{PHASE II \\ IMPLEMENTATION GUIDANCE}

\section{March 1994}

Issued By:

\section{Configuration Management Working Group}

\section{MARTIN MARIETTA ENERGY SYSTEMS, INC.}

Oak Ridge, Tennessee

\section{Prepared for the U.S. Department of Energy under U.S. Govermment Contracts}

DE-AC05-84OR21400 and DE-AC05-760R00001

iii 


\section{CONTENTS \\ CONFIGURATION MANAGEMENT \\ PHASE II \\ IMPLEMENTATION GUIDANCE}

Executive Summary $\quad \ldots \ldots \ldots \ldots \ldots \ldots \ldots \ldots \ldots \ldots \ldots \ldots \ldots \ldots$

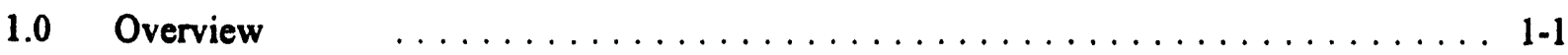

1.1 Configuration Management Initiative $\ldots \ldots \ldots \ldots \ldots \ldots \ldots \ldots \ldots \ldots$

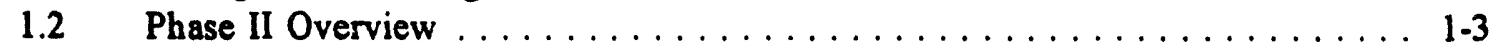

1.3 Phase II Responsibilities . . . . . . . . . . . . . . . . . 1.3

1.3.1 Site and Major Organization Manager ............. 1-3

1.3.2 Responsible Manager . . . . . . . . . . . . . . . . . 1-4

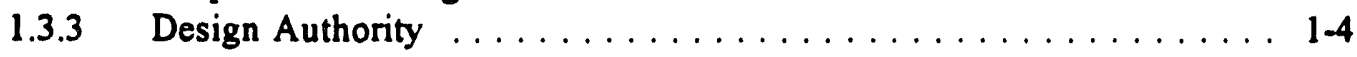

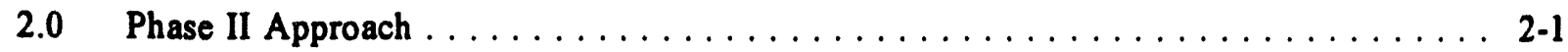

2.1 Steps in the Phase II Process ..................

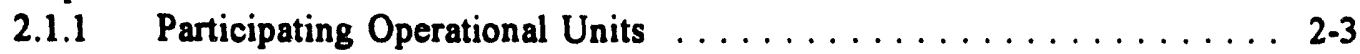

2.1.2 Identify Phase II Configuration Items $\ldots \ldots \ldots \ldots \ldots \ldots \ldots \ldots . \ldots \ldots$

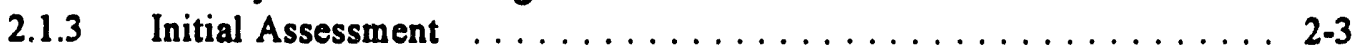

2.1.4 Configuration Management Processes Upgrade . . . . . . . . . 2-3

2.1.5 Requirements, Configuration, and Documentation Upgrade . . . . . 2-4

2.1.6 Material Condition and Aging Management ........... 2-4

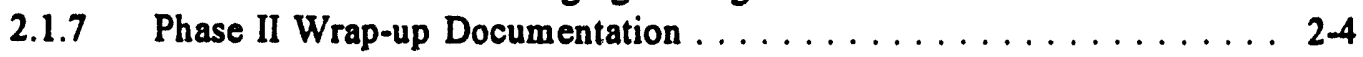

2.2 Expected Phase II Results $\ldots \ldots \ldots \ldots \ldots \ldots \ldots \ldots \ldots \ldots \ldots$

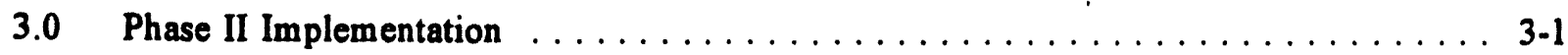

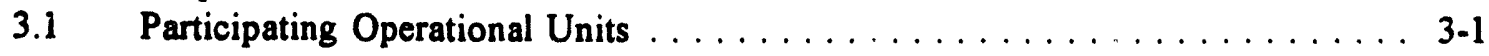

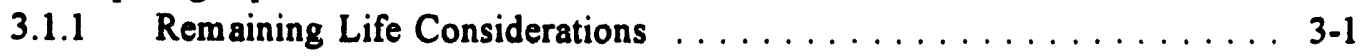

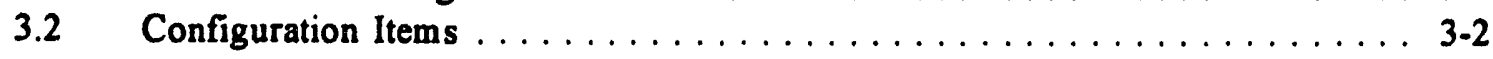

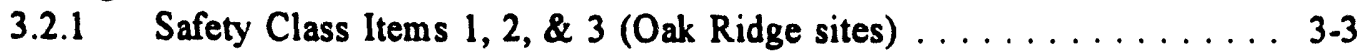

3.2.2 Safety Systems and Design Features for Safety $\ldots \ldots \ldots \ldots$. . . . .

3.2.3 Environmental Protection Items $\ldots \ldots \ldots \ldots \ldots \ldots \ldots \ldots \ldots . \ldots \ldots$

3.2 .4 Safeguards and Security Items $\ldots \ldots \ldots \ldots \ldots \ldots \ldots \ldots \ldots \ldots . \ldots \ldots$

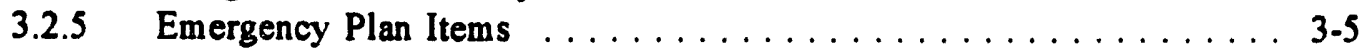

3.2.6 Computer Hardware and Software $\ldots \ldots \ldots \ldots \ldots \ldots \ldots . \ldots \ldots$

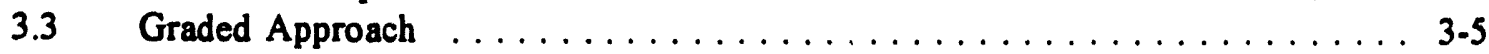

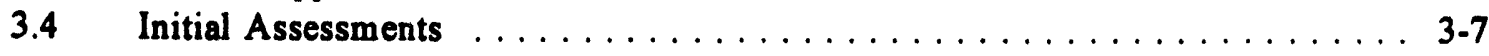

3.4.1 Horizontal and Vertical Assessments . . . . . . . . . . . 3-7

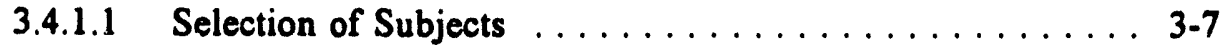

3.4.1.2 Number and Sequence of Assessments . . . . . . . . 3.8

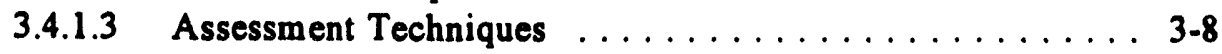

3.4.1.4 Assessment Team ... . . . . . . . . . . . . . . 3-10

3.4.2 Acceptance Standards . . . . . . . . . . . . . . 3-10

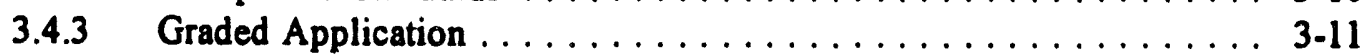




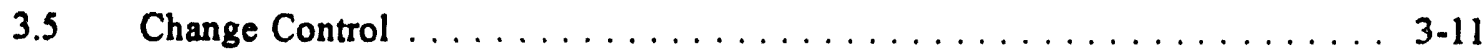

3.5.1 Change Control Process . . . . . . . . . . . . . . . 3-13

3.5.2 Graded Application ..................... 3-14

3.5.3 Change Control Assessment Guidance . . . . . . . . . . . . . . 3-14

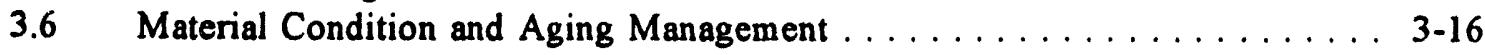

3.6.1 Monitoring Setup . . . . . . . . . . . . . . . . . 3-16

3.6.2 Graded Application . . . . . . . . . . . . . . . . 3-17

3.6.3 Material Condition and Aging Management Assessment Guidance . . 3-17

3.7 Document Control . . . . . . . . . . . . . . . . . . . 3-18

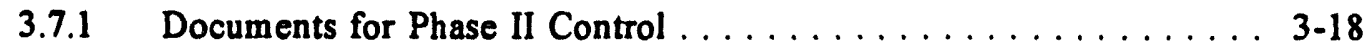

3.7.2 Document Control Process .................. 3-19

3.7.3 Document Updating $\ldots \ldots \ldots \ldots \ldots \ldots \ldots \ldots \ldots \ldots \ldots \ldots$ 3-19

3.7.4 Graded Application ...................... 3-20

3.7.5 Document Control Assessment Guidance ............ 3-21

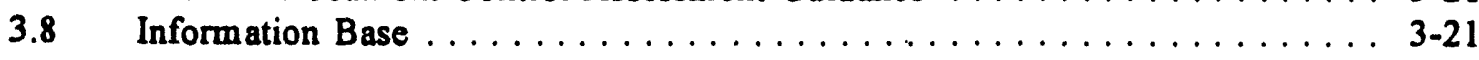

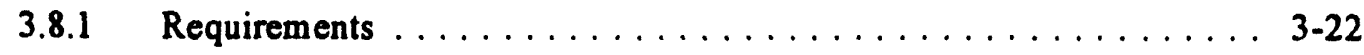

3.8.1.1 Design Requirements $\ldots \ldots \ldots \ldots \ldots \ldots \ldots \ldots \ldots$ 3-22

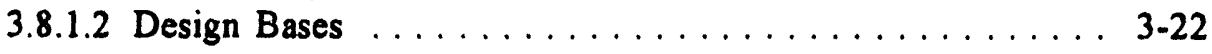

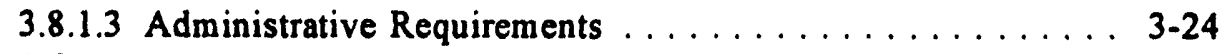

3.8.2 Information Recovery . . . . . . . . . . . . . . . . 3-25

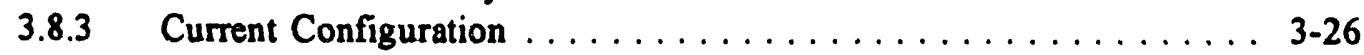

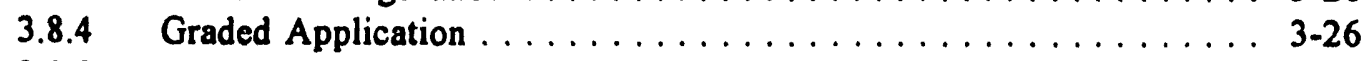

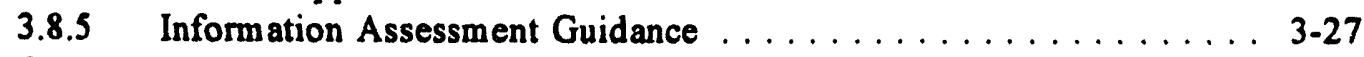

3.9 Configuration Management Processes Upgrade . . . . . . . . . . . . . . . . 3-27

3.10 Requirement, Configuration, and Documentation Upgrade $\ldots \ldots \ldots \ldots \ldots .3 .28$

3.11 Phase II Documentation . . . . . . . . . . . . . . . . . . . . . . 3.29

3.12 Databases . . . . . . . . . . . . . . . . . . . . . . . . 3-29

\section{APPENDICES}

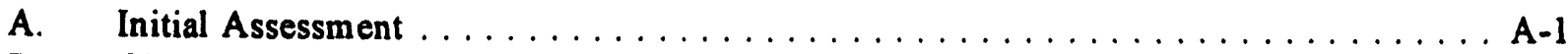

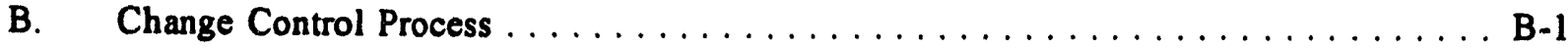

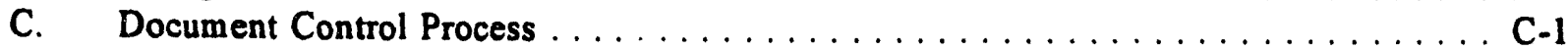

D. Eneigy Systems Configuration Management Working Group $\ldots \ldots \ldots \ldots \ldots \ldots \ldots$ D-1

E. References $\ldots \ldots \ldots \ldots \ldots \ldots \ldots \ldots \ldots \ldots \ldots \ldots \ldots \ldots \ldots \ldots$ 


\section{LIST OF FIGURES}

Figure 1

Figure 2

Figure B-1

Figure B-2
Phase II

$2-2$

Grading Concept

$3-6$

Change Control Process

B-2

Change Control Form 


\section{LIST OF TABLES}

Table 3.4-1

Table 3.4-2

Table 3.4-3

Table 3.5-1

Table 3.6-1

Table 3.8-1

Table 3.8-2

Table B-1

Table C-1
Vertical Assessments $3-9$

Horizontal Assessments 3-10

Example of Assessment Grading 3-11

Change Control Grading 3-15

MCA Management Grading 3-17

Examples of Information

Information Grading

Example Review Checklist B.6

Candidate Documents for Control in Phase II 


\section{ACRONYMS}

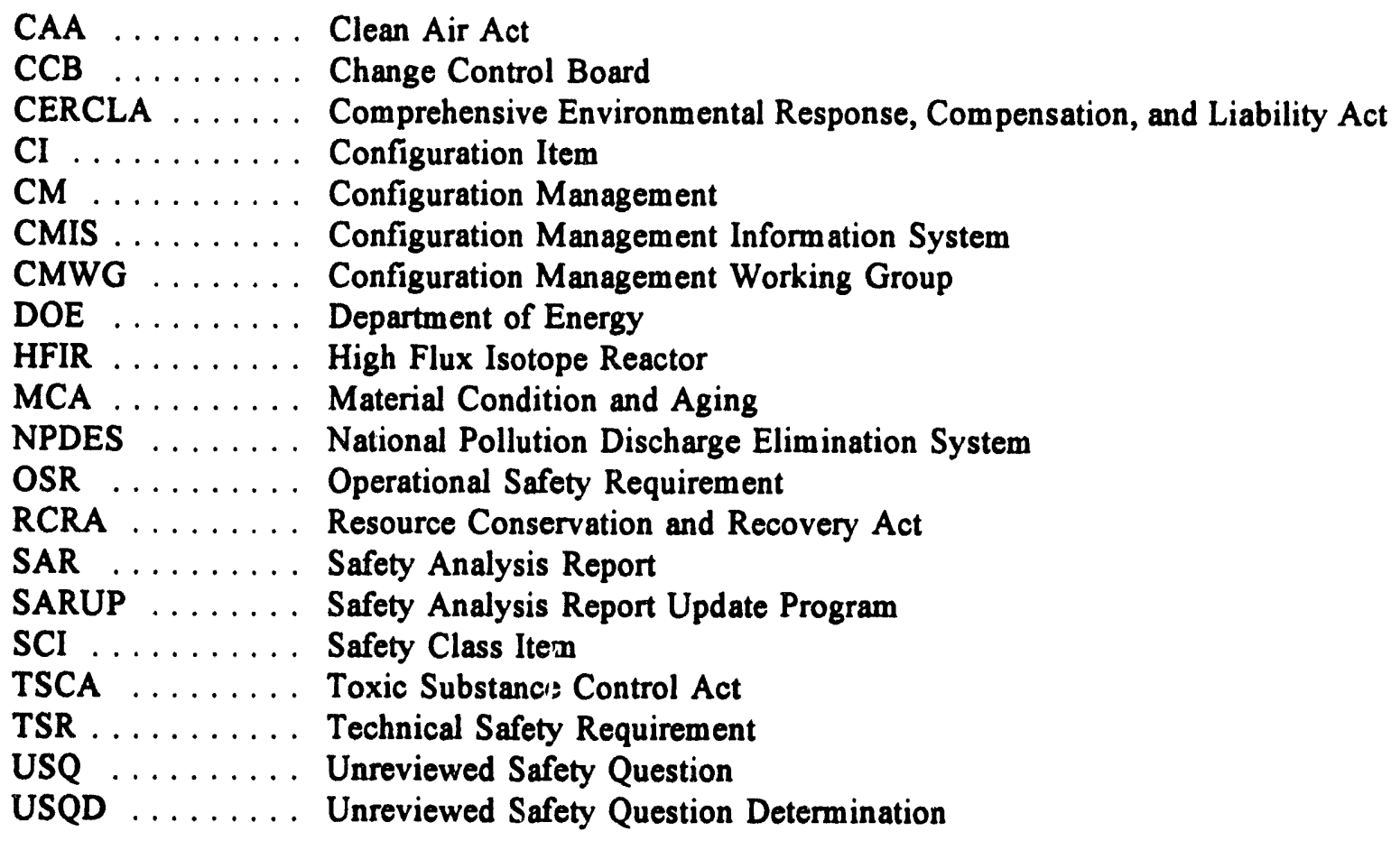




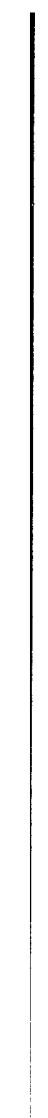

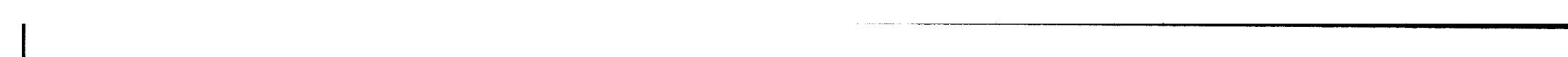




\section{EXECUTIVE SUMMARY}

The operational units' managed by Martin Marietta Energy System, Inc. (Energy Systems) for the Department of Energy (DOE) often involve a degree of risk to the public, workers, environment, or mission success. Risk is inherent in these operational units because they necessarily involve materials and processes that are hazardous, sensitive, or costly. Energy Systems and DOE minimize risk by ensuring that the operational units satisfy requirements established by laws, regulations, and permits; and by good management, design, and operating practices.

Configuration management (CM) is essential to maintaining an acceptable level of risk. It is a set of activities and techniques used to maintain consistency among physical and functional configuration, applicable requirements, and key documents (such as drawings and procedures).

Configuration management is being implemented throughout Energy Systems. Existing programs and practices are being incorporated, not duplicated. Examples include existing control procedures, equipment test and inspection activities, and the results of the Safety Analysis Report Update Program (SARUP).

This document provides guidance for continuing the implementation of $\mathrm{CM}$ in a phased and graded manner. It describes a cost-effective approach to documented consistency with requirements, with early emphasis on items most important to safety and environmental protection.

Energy Systems' basic configuration management expectations and requirements are stated in policy ES-CM-100 (ref. 1) and standard ESS-CM-101 (ref. 2). Energy Systems and DOE-Oak Ridge Operations have established a phased configuration management initiative to implement these requirements. An overview of the initiative is found in CMWG-2/R1, "Configuration Management Overview and Phase I Implementation," (ref. 3), developed by the Configuration Management Working Group. Phase I was intended to ensure that essential change and document control processes were in place for those things that are most important to health, safety, and the environment. In Phase II, which is discussed in this present document, configuration management techniques will be upgraded and expanded to other things of high importance to safety, health, and environmental protection. In Phase III, configuration management practices will be expanded to additional items important to managing risk. In all cases, the application of configuration management will be tailored, or graded, to fit the relative importance of the activity.

Phase II expands from Phase I in three ways. First, it includes more operational units (e.g. low hazard facilities and projects, such as environmental restoration, that handle hazardous materials) and a broader range of configuration items. Second, Phase II expands from Phase I by improving configuration management processes, such as change control and document control, based on a careful review of how well they are working. Third, Phase II rounds out configuration management with additional activities

\footnotetext{
${ }^{1}$ As used here, "operational unit" refers to a facility, activity, process, experiment, or project managed by Energy Systems for Department of Energy.
} 
that were not included in Phase I. These include recovery of missing information that is needed, monitoring of key equipment performance, and upgrading of selected documentation. Phase II should result in a high level of confidence that the risk to health, safety, and the environment has been minimized at each Energy Systems' operational unit.

This guidance document is intended to help responsible line managers and configuration management staff personnel in meeting the Energy Systems configuration management policy and standard. Chapter 1 provides brief overviews of the overall configuration management initiative and of Phase II, including the basic configuration management elements and managerial responsibilities. Chapter 2 presents a flow diagram for Phase II, and a summary discussion of each step involved. Chapter 3 and the appendices provide detailed guidance on how to accomplish each of the Phase II tasks. Included are selection of the items to be placed under configuration management, conducting assessments to determine needs, tailoring configuration management activities to need (graded approach), effective control of proposed changes, surveillance of equipment wear, document control, and recovery of missing information. 


\subsection{OVERVIEW}

Martin Marietta Energy Systems, Inc. (Energy Systems) is engaged in a multi-year initiative to upgrade its configuration management processes to today's expectations. This chapter summarizes the initiative.

Configuration management $(\mathrm{CM})$ is, simply, good management practice. It is good practice for health, safety, and environmental protection; and for supporting compliance, safeguards and security, and mission objectives by protecting production and research capability. It has been shown to significantly aid managers in reducing down time, injuries, environmental damage, and violations of regulations and requirements. It provides tools and information needed for integrating and coordinating activities such that work is done correctly and safely the first time. It also supports efficiency by providing confidence that the operational unit is fully understood by personnel and will function as intended.

Configuration management should not be confused with other management processes such as quality assurance. Configuration management interfaces with and overlaps other processes, but only as a tool. As long as the objectives of configuration management are met--such as by a maintenance program for testing--configuration management is satisfied.

The manager of each Energy Systems operational unit is responsible for configuration management for the operational unit. For this reason, this document is intended to provide flexible "how to" guidance. It also recommends responsibilities, implementation approach, and expected results. It recommends a method for satisfying Energy Systems standard ESS-CM-101, "Configuration Management" (ref. 2). Altemate approaches should be discussed with the appropriate site or major organization representative on the Energy Systems Configuration Management Working Group (CMWG), which developed this guidance. Each site and most major organizations, as well as the DOE - Oak Ridge Operations office, are represented on this group. (See Appendix D for a listing of representatives.)

\subsection{CONFIGURATION MANAGEMENT INITIATIVE}

by:

Configuration management is a tool to support safe, effective, and reliable operations. It does this

- identifying what must be done and the conditions under which it must be done (requirements),

- making important plant features [configuration items, (CIs)] continuously meet the requirements both physically and functionally (configuration), and

- keeping an accurate knowledge base for decisions (documentation).

(Configuration management may be thought of as a triangle with requirements, configuration, and documentation as its points. The triangle is shown as Figure 1 in CMWG-2/R1, "Configuration Management Overview and Phase I Implementation Guidance," ref. 3.)

\footnotetext{
${ }^{1}$ As used in this document, "operational unit" refers to a facility, activity, process, experiment, or project managed by Energy Systems for the Department of Energy.
} 
The key to effective configuration management is to establish these three points for each important configuration item, and then to hold the three consistent as changes occur to the plant features over time. Thus, controlling changes and documents are essential elements of configuration management.

Although configuration management has always existed in some form throughout Energy Systems, past and present practices often do not satisfy current expectations. Examples of not meeting current expectations include cases in which:

- requirements, and their bases, are not known to the degree desired;

- $\quad$ plant features do not completely satisfy known requirements due to changes;

- as-built documents are not up to date, and

- management systems are not sufficient to completely control changes and documents such that consistency between requirements, configuration, and documentation can be maintained.

Energy Systems recognizes that its existing configuration management processes often do not meet today's Department of Energy (DOE) and industry standards. As a result, Energy Systems is engaged in a multi-year initiative to improve configuration management processes. This initiative is outlined in reference 3.

The configuration management initiative is graded and phased. In this concept, graded means that the effort, or rigor, will be commensurate with the hazards and overall risk the plant feature poses to people, the environment, and other company concerns. Phased means that upgrade activities will be in stages to make any required backfitting more manageable and to gauge progress. Together, the phased and graded concepts will be used to focus first on those activities that appear to bring the highest benefit for their cost. follows:

The phases of the Energy Systems configuration management initiative may be summarized as

- Phase I was a short, focused effort to ensure that existing change and document controls are adequate for those items most important to protecting health, safety, and the environment. (Phase $I$ is described more fully in reference 1.)

- Phase II will broaden the application of configuration management to other items important to health, safety, and the environment. It will establish consistency among requirements, configuration, and documentation for these configuration items. In addition, it will upgrade configuration management processes and the information base needed to support these processes. Phase II is outlined in this document.

- Subsequent phases will extend less-rigorous configuration management processes and information upgrading to other items that are important for reasons other than health, safety, and environmental protection.

Another characteristic of the configuration management initiative is that it relies heavily on existing programs, although those progra is may need to be augmented in cases. For example, the configuration management initiative relies on the Safety Analysis Report Update Program (SARUP), as 
well as on past operating experience, as a basis for safe operation; and on preventive maintenance programs for ensuring equipment continues to meet its requirements.

The configuration management initiative will use or, if necessary, improve existing management processes. It will cause the creation of new processes only where none exist.

The style of configuration management traditionally applied to operating facilities and activities differs from that used for projects such as design work or environmental restoration. However, the two share the basic elements discussed in this guidance. Both projects and operations should be able to adapt this guidance.

\subsection{PHASE II OVERVIEW}

Phase II applies to Energy Systems operational units with functions important to health, safety, and the environment. This generally includes facili es, activities, and projects with, or in the process of: developing, a safety analysis report and/or environmental permit. (Section 3.1 discusses which operationall units should participate.)

The specific objective of Phase II is to ensure:

- important features of Energy Systems operational units conform to health, safety, and environmental protection requirements;

- the physical and functional characteristics of these features are accurately reflected in documents used for decisions affecting health, safety, and the environment; and

- management processes are in place to maintain these conditions

An important part of Phase II is the initial assessment, which is a detailed review of the strengths and weaknesses of the existing knowledge base, documentation, field conditions, and control processes. In most cases, the assessment will provide a basis for upgrading existing knowledge, documents, and processes based on real need as demonstrated by their actual performance. (Upgrading existing processes instead of creating new ones should avoid unnecessary work, cause less disnuption, and be less likely to create new problems.) In some cases, the assessment will identify a need to correct field conditions.

\subsection{PHASE II RESPONSIBILITIES}

General configuration management responsibilities are discussed in references 1,2 , and 3 . These describe responsibilities of senior management at site and major organization levels, line managers, configuration management coordinators, the design authority and others. Suggested specific roles and responsibilities during Phase II are summarized below.

\subsubsection{Site and Major Organization Manager}

The site and major organization managers have overall responsibility for implementing Phase II configuration management at the site or major organization levels. This includes: 
- providing site or organization-specific Phase Il implementation plans;

- $\quad$ selecting Phase II facilities, activities, processes, and experiments;

- $\quad$ providing Phase II training as needed; and

- coordinating initial assessments to ensure completeness and efficiency.

The manager may choose to delegate these responsibilities to his configuration management coordinator.

\subsubsection{Responsible Manager}

The line manager responsible for a facility, activity, process, or experiment is referred to as the responsible manager. The responsible manager has overall responsibility for implementing Phase II. This includes:

- providing a Phase II implementation plan specific to the operational unit;

- $\quad$ identifying configuration items;

- planning, scheduling, and carrying out the initial assessment;

- implementing improvements to the change and document control processes, as needed;

- identifying and recovering required information for each configuration item;

- $\quad$ recovering or re-creating design requirements, when justified;

- identifying and updating/creating configuration item documents;

- ensuring degradation of systems, structures, and components is adequately monitored and corrected; and

- applying an appropriately graded approach to the initial assessment, change and document control processes, material condition and aging management, and information requirements.

Situations arise in which responsibility is not clearly defined. For example, who is responsible for a fire protection system inside a particular building? In such cases, the manager responsible for the facility should coordinate with other responsible managers to establish interfaces and authorities. Who has the final authority should be documented and have the concurrence of the site or major organization manager.

\subsubsection{Design Authority}

The design authority is the person or organization with the knowledge, understanding, and authority to make changes to the design of a facility or system. This entails knowing the design requirements and design basis, and being able to judge the effects a proposed design change might have. In Phase II, the design authority is responsible, under the direction of the responsible manager, for:

- $\quad$ supporting the initial assessment, especially with identification of configuration items, design requirements, and design bases;

- supporting evaluations and reviews of proposed changes to configuration item or configuration item documentation to ensure compliance with known design requirements;

- supporting change control and document control process improvements; 
- recovering or re-creating missing design requirements and design bases, when needed; and

- supporting material condition and aging management by identifying design requirements and margins. 
Page 1-6 intentionally left blank. 


\subsection{PHASE II APPROACH}

The philosophy behind Phase II is to build on existing knowledge and processes. Most Energy Systems operational units have the elements of configuration management in place, but some do not meet today's expectations. To build on what is in place, Phase II is largely based on a systematic review of the existing configuration management elements at the operational unit, compared with current Energy Systems expectations. This review, called the initial assessment in configuration management terminology, provides a basis for making improvements where they are needed.

\subsection{STEPS IN THE PHASE II PROCESS}

One approach that can be taken to complete Phase II is outlined in Figure 1 and briefly discussed below. Additional guidance on how to accomplish Phase II activities is provided in chapter 3. The activities should be tailored to fit the basic operational unit. Tailoring should consider risk to health, safety, and the environment; the complexiiy of the operational unit; mission; and other factors identified by the responsible manager.

For simplicity, several important activities such as planning and training are not called out in the figure. An explanation of these is not needed since they are common management functions. A few points are essential to Phase II success, however, and should be considered carefully to ensure the effort is both adequate and efficient. In addition to normal planning steps (e.g., cost, resources, and schedule), the Phase II plan should address:

- the site/major organization plan (obtained from the site/major organization CM coordinator),

- configuration management concepts and methods training (see below),

- interfaces with supporting organizations (e.g., engineering, maintenance, facility safety, and environmental management),

- pending transitions to or from another stage of the life cycle, and

- the appropriate sequence (most important to less important) for addressing configuration items.

The plan does not have to be elaborate: it should be appropriate for the risk and complexity of the operational unit. The site/major organization CM coordinator can help develop the plan.

General Phase II training should address:

- basic configuration management concepts and terminology (refs. 1, 2, and 3),

- $\quad$ Phase II objectives and outline (Chapter 2, this document)

- basic change control and document control concepts (Chapter 3, this document)

- general employee responsibilities in configuration management.

The individuals and teams performing tasks such as the initial assessment should also be trained in those tasks (Chapter 3, this document). The configuration mana ment working group is developing generic training materials that may be used. 


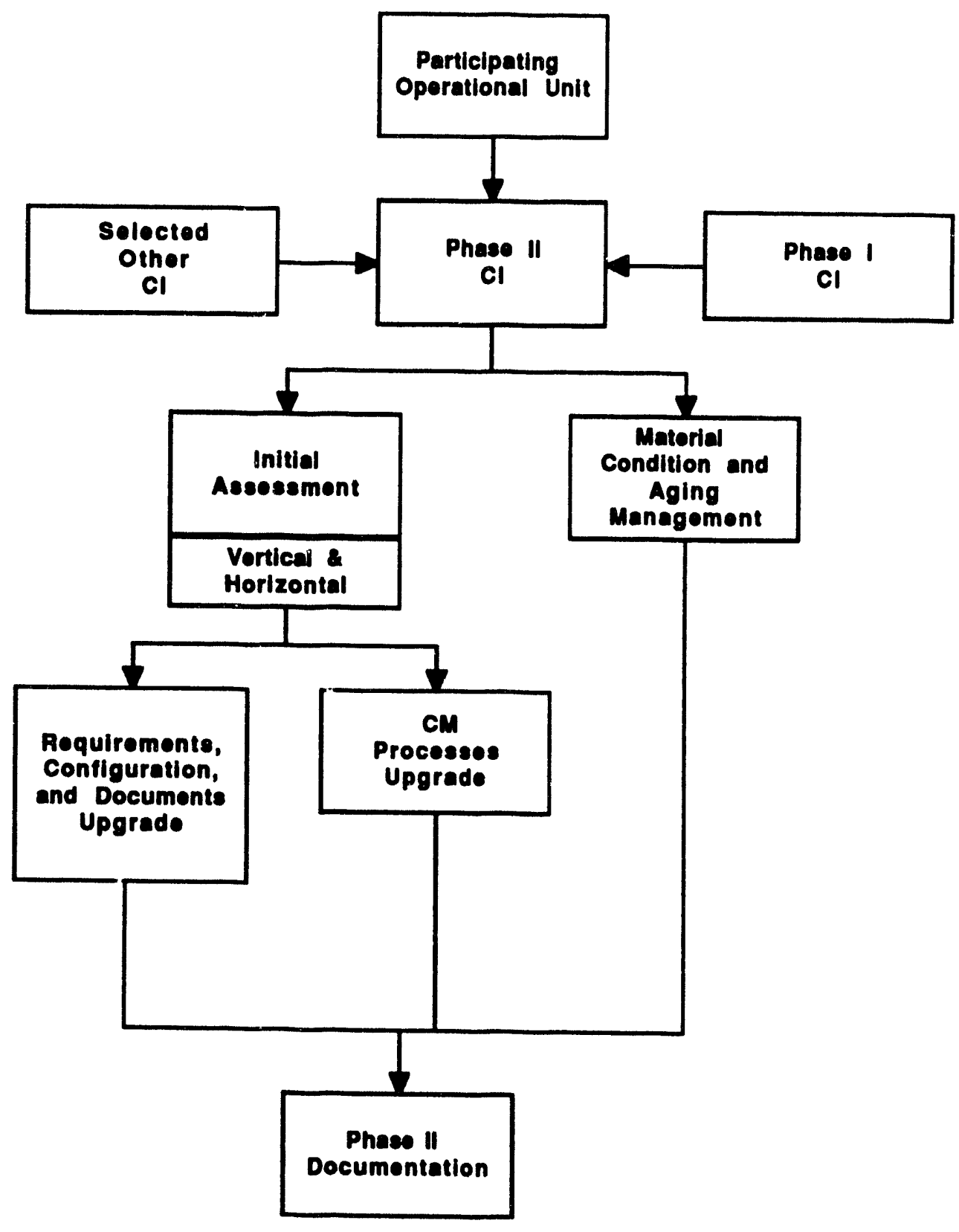

Figure 1

PHASE II 


\subsubsection{Participating Operational Units}

The first step is to identify the operational units that will participate in Phase II. These are identified in section 3.1. Identification should be made at the site or major organization level.

\subsubsection{Phase II Configuration Items}

The second step is to identify which configuration items should be addressed at each participating operational unit ${ }^{1}$. The most important configuration items were identified as part of Phase I for a small number of facilities. Phase II adds to these other configuration items that are important (i.e., pose risk) to protecting groups of people (i.e., the public and groups of on-site workers) or the environment.

Phase II configuration items should be identified by the responsible manager, with input from supporting organizations such as the customers (e.g., DOE), facility safety, environmental management, the design authority, security, and utilities (e.g., fire protection or power). Section 3.2 provides additional guidance for selecting Phase II configuration items.

\subsubsection{Initial Assessment}

The third step, the initial assessment is intended to identify programmatic weaknesses such as uncontrolled modifications, inaccurate as-built drawings, and missing design requirements ${ }^{2}$. Identifying these weaknesses provides a basis for deciding what changes are needed to have effective configuration management in place for the future. Section 3.4 provides additional guidance for performing the initial assessment.

The responsible manager should identify the assessment team members, provide them training, and ensure they have sufficient time and access to people, documents, and the system or activity being reviewed.

\subsubsection{Configuration Management Processes Upgrade}

Based on the findings of the initial assessment, the fourth step is to upgrade configuration management processes such as change control. Weaknesses may be demonstrated by inconsistencies among the identified requirements, actual configuration, and documentation reviewed in the assessment. Process weaknesses can be identified from this information by studying the related procedures or instructions and training. Process improvements such as upgrading procedures and giving training can then be done. This is particularly applicable to the $C M$ processes established during Phase I for the initial set of configuration items. Section 3.9 provides additional guidance for upgrading configuration management practices.

Upgrade actions should be initiated and controlled by the responsible manager. Assistance can

\footnotetext{
${ }^{1}$ Reference 2 defines the initial assessment to include identification of configuration items. This document, however, has split that function out to clarify the overall Phase II process.

${ }^{2}$ Ibid. 
be obtained from the site or major organization CM coordinator or from similar operational units that have been successful in the area of interest.

\subsubsection{Requirements, Configuration, and Documentation Upgrade}

The initial assessment may identify a need to upgrade the information, actual configuration, or documentation of individual configuration items. Specific problems such as missing information, inaccurate as-built drawings, system misalignment, inadequate mairtenance, and modifications that have violated design requirements may be found. These problems need to be corrected on the system or activity in which they occur.

Upgrade actions should be initiated and controlled by the responsible manager. A prioritized long term plan including a funding request may be required.

\subsubsection{Material Condition and Aging Management}

Material condition and aging (MCA) management is the process by which systems, structures, and components (a subset of configuration items) are monitored to make sure they do not wear out or otherwise fall outside their required perform ance limits. The Phase II systems, structures, and components should be examined to identify which can degrade to outside their required limits due to wear, aging, or environmental conditions; and ensure they are placed in a monitoring program.

The responsible manager should identify the Phase II systems, structures, and components for material condition and aging management. Assistance from facility safety, engineering, test and inspection, and maintenance personnel may be necessary.

\subsubsection{Phase II Wrap-up Documentation}

Finally, wrap-up documentation should be prepared to record what was done in Phase II. Wrap-up documentation will serve as proof that the items most important to the health and safety and the environment are adequately understood and controlled. Section 3.11 provides additional guidance on the content and quality the documentation needs.

The Phase II wrap-up documentation should be placed on file, and a copy provided to the site or major organization coordinator. The site/major organization coordinator should compile this information for all participating operational units and provide it to the site/major organization manager, with a copy to the Energy Systems Central Policy Manager.

\subsection{EXPECTED PHASE II RESULTS}

At completion of Phase II the following conditions will exist:

- configuration items that are important to health, safety, and the environment are identified $^{3}$;

\footnotetext{
${ }^{3}$ Except health and safety of individual workers. See section 3.2 .
} 
- health, safety, and environmental design and administrative requirements applicable to each of these configuration items are known ${ }^{4}$ and clear;

- the physical and functional configuration of each of these configuration items are consistent with known health, safety, and environmental requirements;

- documents used for decisions affecting health, safety, and the environment accurately reflect the known requirements and physical and functional configuration of the configuration item;

- a change control process is functioning effectively for those configuration items that insures the changed item satisfies the intent of the change and meets known requirements;

- a document control process is functioning effectively that ensures that documents used for important decisions are current and accurate; and

- systems, structures, and components meeting Phase II configuration item criteria are monitored for the degradation of important parameters and replaced prior to failing to meet design requirements.

These conditions will be tailored to fit the health, safety, and environmental protection needs of the operational unit.

4See Section 3.8 discussion of how much should be known. 
Page 2-6 intentionally left blank 


\subsection{PHASE II IMPLEMENTATION}

The previous chapters outlined the Energy Systems configuration management initiative and the scope, objectives, and recommended approach for Phase II. This chapter provides additional "how to do it" guidance for the various Phase II activities. Included are sections on the configuration management practices of assessment, change control, document control, information base, and material condition and aging management. Guidance is also given on the selection of operational units to participate in Phase II, the selection of configuration items each unit should include, ideas for grading (making configuration management application commensurate with need), and brief discussions on related subjects.

The site or major organization CM coordinator should be consulted for additional advice, interpretation of this guidance, or alternative approaches.

\subsection{PARTICIPATING OPERATIONAL UNITS}

Phase II includes operational units that have either environmental permits or other requirements, or a safety analysis report indicating potential impact on the public on groups of workers (as opposed to individual workers). This includes any operational units that meet one or more of the following criteria. Exceptions may be taken for remaining life considerations as described below.

- Facilities classified as Category 1, 2, or 3 by the Facility Safety Manager;

- Oak Ridge facilities classified as high, moderate, or low hazard by the Facility Safety Manager;

- Portsmouth and Paducah facilities with potential hazards to workers and the public as identified by the Facility Safety Manager;

- Operational units with environmental permits or regulated hazardous materials;

- Safeguards and security systems and activities which are relied upon to protect the configuration items most important to safety; or

- Facilities or activities providing evacuation and protection of workers after an accident.

\subsubsection{Remaining Life Considerations}

Due to the time needed to implement significant configuration management upgrades, it may be inappropriate for some operations to do more than a minimum (except to correct identified near-term hazards or significant risk). The following guidelines should be considered in determining effort:

- If the operation is known to be shutting down (e.g., DOE has announced it) or transitioning to another phase (see below) by January 1996, Phas! ij actions are probably inappropriate. Controls initiated or confirmed in Phase I should be continued.

- If the operational unit is known to be shutting down or transitioning to a other phase by January 1999, perform the initial assessment and subsequent configuration 
management prosess upgrades, but consider limiting any information gathering (see section 3.8) to essential information and material condition and aging management (see section 3.6) activities to the most important systems, structures and components. - If the operation is known to be shutting down or transitioning to another phase by January 2004, perform the initial assessment and subsequent configuration management process upgrades, but consider limiting any information gathering (see section 3.8 ) to important information that is both likely to be needed and difficult to recover.

If, however, Phase II participation is limited due to a planned transition between phases (e.g, from design to construction, construction to operation, operation to shutdown, and shutdown to decontamination and decommissioning) special preparations should be made to support the next phase. For example, the receiving organization may need to know what is important, to get as much information on each item of interest as practical, and customized documentation such as as-built drawings.

\subsection{CONFIGURATION ITEMS}

Like Phase I, Phase II includes items important to (i.e., posing significant risk) protection of health, safety, and the environment. Phase II includes the configuration items addressed in Phase I, plus additional ones. The configuration items that should be addressed in Phase II are:

- $\quad$ safety class items $1,2, \&$ the most important $3^{\prime}$ (Oak Ridge sites),

- $\quad$ safety systems and design features for safety,

- environmental protection items to control hazardous materials or effluent and discharges,

- safeguards and security items which protect configuration items most important to safety, and

- items required to support emergency plans.

These items and their identification are discussed further below.

Additional items may be included, if the responsible manager so wishes. This might be the case, for example, when an item is called for in a baseline order, law, or regulation; or is essential to the operational unit's mission. These items are considered optional for completion of Phase II. (If included, they should be treated as a lower priority than configuration items that are in the Phase II scope.)

The scope of the configuration items included in Phase II represents a small expansion from Phase I. Phase I addressed only the configuration items most significant to health, safety, and the environment. Phase II includes the configuration items in Phase I plus the most important safety class item (SCI) 3 items, the remaining items important to environmental protection, and the safeguards and security or emergency plan items whose failure can lead to unacceptable consequences to the public or site workers.

\footnotetext{
${ }^{1}$ Some safety class 3 items may be excluded, as discussed in Section 3.2.1.
} 


\subsubsection{Safety Class Items $1,2, \& 3$ (Oak Ridge sites)}

Safety class items are outputs of the Safety Analysis Report Update Program (SARUP) at the Oak Ridge sites. The safety class items are identified in the Safety Analysis Report, Technical Safety Requirements, Facility Safety Evaluation, or Safety Study for each facility with more than standard industrial hazards. They are those items that are essential to the protection of the public (SCI 1), site workers (SCI 2), and the immediate area workers (SCI 3). In cases in which the final list of safety class items is not complete, a listing of candidate safety class items, part of the SARUP Phase IA report, may be obtained from the Facility Safety organization.

Only those SCI 3 items that protect groups of workers, as opposed to individuals, should be included in Phase II. (A later phase of configuration management implementation may address the others. If significant hazards to individuals are identified in the course of Phase II, they should be handled as appropriate using existing corrective action programs.) For example, a building evacuation alarm might be appropriate, whereas a ladder or a machine guard would not.

Examples of safety class items include criticality alarm systems, hydrogen fluoride tanks, and the High Flux Isotope Reactor's (HFIR) reactivity control system.

Assistance in identifying safety class items for each facility may be obtained from the Facility Safety Evaluation Team at each facility, or from the site Facility Safety organization. Assistance in determining which SCI 3 items should be included may be obtained from the analyst who identified the item; this person can be identified by the Facility Safety Evaluation Team or the Facility Safety organization.

\subsubsection{Safety Systems and Design Features for Safety}

Safety systems and design features for nuclear safety are identified, in general terms, in the Safety Analysis Reports at Portsmouth and Paducah. The items are considered essential to the protection of the public and site workers. The list of items is being revised as part of the Safety Analysis Report Upgrade Program at each site. Examples of design features for nuclear safety and safety systems at Portsmouth and Paducah include autoclaves and autoclave pressure relief systems, respectively.

At Oak Ridge sites, safety systems and design features for safety are identified in older Safety Analysis Reports and Operational Safety Requirements (OSRs), but will be replaced by safety class items when the new Safety Analysis Reports and OSRs are approved by DOE. Until superseded, they should be included in Phase II. Safety systems and design features for safety generally equate to SCI 1, 2, and 3 at Oak Ridge. That is, they may serve to protect the public, general site workers, or individuals. The responsible manager may assign the operational unit's safety systems and design features for safety into one or more of these categories and treat them as SCI 1, SCI 2, or SCI 3, respectively, for Phase II. The candidate safety class item list (see subsection 3.2 .1 ) may be used to make these assignments. Assistance in making these assignments may be obtained from the Facility Safety organization.

Assistance in identifying safety systems and design features for safety for each facility may be obtained from the site Facility Safety organization. 


\subsubsection{Environmental Protection Items}

The items of interest in Phase II are those meeting two criteria. First, they are identified or implied (i.e., not named, but must function to keep the permit valid) in an environmental permit, regulation, or other commitment to a federal, state, or local environmental agency. (In cases where a permit has been requested, but not yet received, the items of interest are those identified or implied in the application.) Second, failure of the item could lead to actual environmental insult, not just a permit violation.

The items important to meeting the following laws should be included in Phase II:

- Clean Air Act (CAA) - deals with effluent to the atmosphere;

- National Pollution Discharge Elimination System (NPDES) - part of the Clean Water Act which addresses discharges of waste water directly to surface waters;

- Resource Conservation and Recovery Act (RCRA) - regulates hazardous waste from its generation to permanent disposal;

- Toxic Substances Control Act (TSCA) - special controls for toxic materials; and

- Comprehensive Environmental Response, Compensation, and Liability Act (CERCLA - requires investigation and remediation of hazardous waste sites where release to the environment has occurred or could occur.

Examples of environmental protection configuration items include tanks or drums of hazardous materials, waste water cleanup systems, and stack monitors.

These items can be identified by reviewing the permits that apply to the operational unit. In most cases, the important items are called out in the permit. Some review of the analyses, drawings, and documents that are submitted with the permit application may be useful to identify items that are assumed to be in a particular configuration - and thus need configuration management - for the application or permit to be valid.

Assistance in identifying environmental protection items may be obtained from the site Environmental Management organization.

\subsubsection{Safeguards and Security Items}

The items of interest are those judged most important to protecting other configuration items which are most important to facility safety: SCI 1 or 2 (Oak Ridge), and the safety systems and design features for safety that were addressed in Phase I. Failure of these safeguards and security items to perform as intended could allow an accidental or intentional human action to cause failure of the protected item, leading to unacceptable consequences to the public or site workers.

In practice, it may only be practical to identify area or building safeguards and security measures, such as building access controls and the area fence, but not be concerned with protecting individual items important to facility safety.

Examples of Safeguards and Security configuration items include physical items, such as intrusion alarms or doors, and activities such as control of weapons (whose discharge could rupture a tank, for example). 
A listing of items important to Safeguards and Security is being developed by Energy Systems Protective Services. Assistance in identifying such items can be obtained from the Plant Security group and Protective Forces Group, or the Protective Systems Group serving each site from Y-12. Assistance in determining which safety-related items should be protected may be obtained from the Facility Safety Evaluation Team or the Facility Safety organization.

\subsubsection{Emergency Plan Items}

The items of interest are those helping protect people by alerting them to danger and helping them get out of harm's way. These items are generally specified or implied in site emergency preparedness plans or facility plans. They may also be identified by industrial standards, fire protection procedures, and similar sources concerned with personnel safety.

Examples of emergency plan configuration items include fire doors and public address systems.

Assistance in identifying these configuration items can be obtained from the site Emergency Preparedness Coordinator and the site Fire Protection Engineering organization.

\subsubsection{Computer Hardware and Software Control}

Computer hardware and software that perform functions (e.g., controlling equipment, engineering calculations, and databases) important to health, safety, and the environment should be included as configuration items in Phase II. Some of these important computer systems can be identified by the fact that they directly control or support other identified configuration items or are used directly for functions such as access control that are otherwise included in Phase II. Others, such as personal computer software used by designers or safety analysts, can be identified by consulting their users. Still other such computer systems can be identified by judging (based on the safety analysis and environmental permit/commitments) which hardware/software can, if they do not operate properly, produce unacceptable risk. For example, the computer software and hardware controlling a valve would be important if flow control were important to the safety analysis, but the computer system would not be a Phase II configuration item if only the pressure boundary of the valve were important.

\subsection{GRADED APPROACH}

Grading means making effort proportional to need. For Phase II, this means meeting health, safety, and environmental protection requirements in a cost-effective way. The purpose of grading is to focus resources where they will do the most good.

Figure 2 illustrates the grading concept as it can be applied to activities such as change control. Conceptually, the horizontal axis is the "universe" of configuration items in an operational unit, running from the most important on the left (e.g., SCI 2) to less important on the right (e.g., non-safety). The vertical axis represents the relative rigor or effort that is appropriate for each level of item.

To illustrate, assume there are three small piping systems in one facility: one each of safety class items (SCI) 2 and 3, and one with no safety function. The SCI 2 system processes a large quantity of hydrogen fluoride, the SCI 3 system processes ammonia, and the non-safety system processes chlorinated water. Because of the risk to a large number of people, we would want the SCI 2 system to have a 
tightly-constructed change control process requiring detailed safety analysis, extensive review, and careful testing. This might be on the left of Fig. 2. By contrast, the non-safety system poses little risk. It can have a simple change control process requiring a minimum of safety analysis (enough to protect the safety functions of other systems), review, and testing. Between the two, the SCI 3 system would require a change control process with enough safety analysis to protect the SCI 2 system functions and the facility personnel, and a moderate amount of review and testing. (In practice, it may be most practical to use the same change control process for all three systems.)

Note that this figure is only for illustration of the concept of grading. It does not necessarily apply to any given configuration management activity or operation.

Phase II grading is primarily based on risk to the public, site workers, and the environment. Other factors that should be considered include complexity (e.g., complex systems normally require more information, more documentation, and more sophisticated change controls than simple systems), operational status (e.g., the risk from a shutdown facility is often significantly less than the same facility during operation), and remaining life (e.g., an operating facility expecting shutdown in the near future would invest less effort than one expecting to remain operational - see section 3.1 ).

Sections 3.4 - 3.8 provide guidance for grading assessments, change control, material condition and aging management, document control, and information requirements. This guidance is in the form of suggested levels of effort for the left and right sides of Fig. 2.

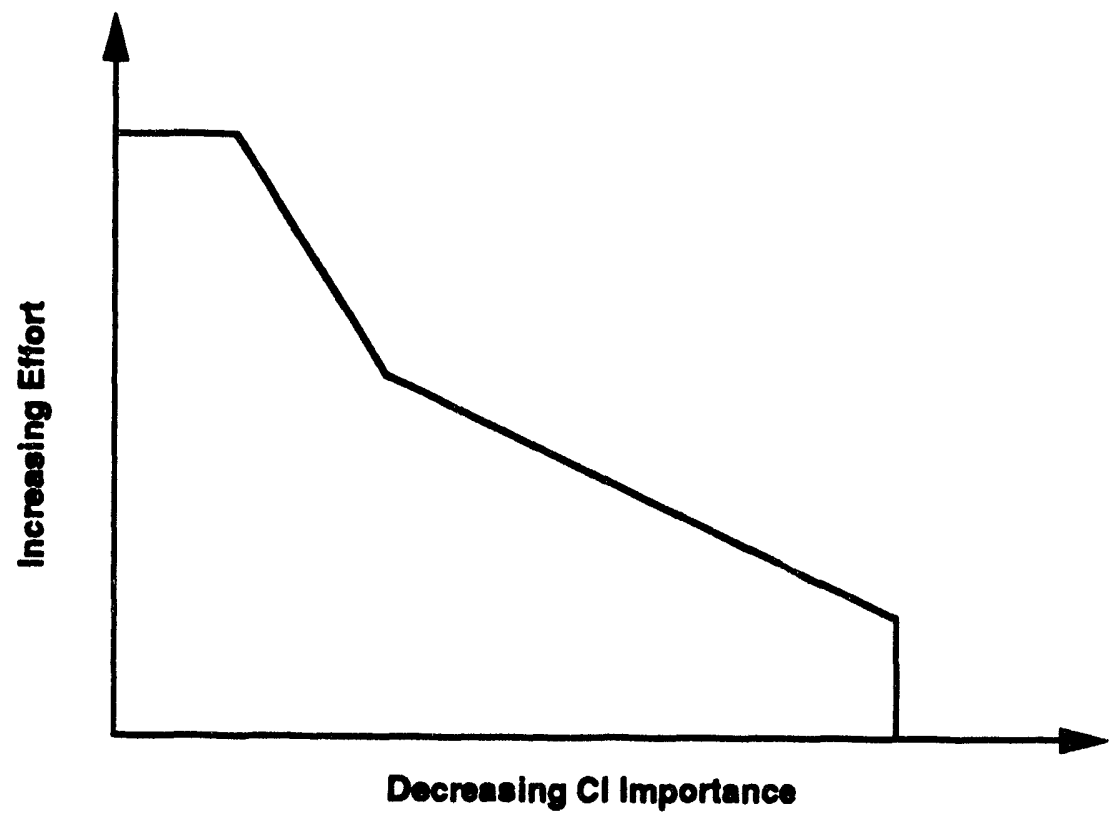

Figure 2 GRADING CONCEPT 
An assessment is a review to confirm that configuration management is effective or to identify weaknesses. The initial assessment ${ }^{2}$ is a look at existing management processes that affect health, safety, and the environment. It is intended to see what additions or upgrades, if any, are needed. It provides the basis for improvements to be made in Phase II.

The initial assessment should be performance based: it should look at results, not just theories and procedures. That is, the initial assessment should determine whether the health, safety, and environmental requirements of an installed system are known, whether the system can meet those requirements, and whether documents used for important decisions are accurate.

Assessments are conducted in each phase of configuration management implementation and beyond. Phase I used a "desktop" comparison of existing change and document control processes to models. It provided some confidence that the most important items will operate safely. Phase II uses the more complete and formal initial assessment (discussed below) that looks at configuration items, requirements information, and documentation in some detail. After completion of Phase II, assessments will be conducted periodically to verify performance.

If an examination of existing assessment processes demonstrate that they satisfy the objectives of the initial assessment, they can be used in lieu of the methods suggested here.

\subsubsection{Horizontal and Vertical Assessments}

The initial assessment typically has vertical and horizontal elements. Together they can provide a cross section of current performance. The horizontal assessment takes a single configuration management process, such as change control, and looks at it across many configuration items and systems to ensure it is functioning as required for the different types of systems and components. The vertical assessment is a head-to-toe focus on a single system or activity, such as the liquid low level waste system. The assessment starts by identifying design and administrative requirements; goes to the system in the field or building to see how it actually looks and functions; and then checks change packages, procedures, analyses, training, records, and other performance information. The result is information on how well existing configuration management processes work for an actual system. With this information, corrective actions can be focused where they are needed without damaging successful management processes.

Some factors in conducting assessments are discussed below.

\subsubsection{1}

Selection of Subjects

Ideally, the sample system or activity selected for a vertical assessment should be one of those in involved in Phase I, if applicable. Otherwise it should be a system added in Phase II that is of typical complexity for the operational unit. When a second vertical assessment is appropriate (see below), it

\footnotetext{
${ }^{2}$ Called "initial" to distinguish it from the periodic assessments to be carried out after configuration management implementation. Reference 2 defines the initial assessment to include identification of configuration items. This document, however, has split that function out to clarify the overall Phase II process.
} 
should pick a system or activity that is important to environmental protection if the first assessment was on a safety system, or safety if the first assessment was on an environmental protection system.

The first horizontal assessment should focus on the change control process. A second horizontal assessment, if appropriate (see below), should select whatever subject the vertical assessment indicates is significantly weak. For example, if the vertical assessment finds that the sample system(s) have inadequate maintenance document controls, the second horizontal assessment should focus on that area across many systems.

\subsubsection{Number and Sequence of Assessments}

There may be situations in which more than one vertical and/or horizontal assessment should be performed. This could be the case when it is particularity important to confirm the configuration management process is working, as when numerous complex systems are involved or when failure could lead to potentially unacceptable consequences. Additional assessments can lower the chances of missing important programmatic weaknesses or wasting attention on isolated problems.

Tables 3.4-1 and 3.4-2 suggest the minimum number of vertical and horizontal assessments, respectively, that should be conducted for various situations.

The vertical assessments should be performed before horizontal assessments. Vertical assessments may indicate programmatic weakness which should be targeted in horizontal assessments.

There may be situations in which the assessments need not be done on an operational unit. Examples of situations for which an exception may be justified are:

- there is a vertical assessment on a very similar operational unit that can be defended as applicable,

- a horizontal assessment of the change control process may' be unnecessary if a decision has already been made to replace the process with a new one known to work (such as from another facility), or

- a recent (within one year) assessment is confirmed to satisfy the objectives and standards of the initial assessment.

A post-implementation assessment may be performed, at the discretion of the responsible manager, after the configuration management process improvements are made. The post-implementation assessment should use the same vertical and horizontal assessment teciniques to confirm the success of the adopted processes.

\subsubsection{Assessment Techniques}

Appendix A summarizes how vertical and horizontal assessments can be done. The assessment process should be tailored to the operational unit because it is looking for actual results, not procedural theory. 
Table 3.4-1

VERTICAL ASSESSMENTS

\begin{tabular}{|c|c|c|c|}
\hline \multicolumn{2}{|c|}{ The operational unit has configuration items: } & \multicolumn{2}{|c|}{ Vertical assessmeats are recommended on: } \\
\hline - & $\begin{array}{l}\text { SCI } 1 \text { or } 2 \text { items; or safety systems or } \\
\text { design features for safety }\end{array}$ & $\bullet$ & Two systems with these items \\
\hline plus & $\begin{array}{l}\text { SCI } 1 \text { or } 2 \text { items; or safety systems or } \\
\text { design features for safety } \\
\text { Environmental protection items }\end{array}$ & plus & $\begin{array}{l}\text { One system with these items } \\
\text { One system with these items }\end{array}$ \\
\hline • & $\begin{array}{l}\text { SCI } 3 \text { items, SCI } 3 \text { - equivalent safety } \\
\text { systems and design features for safety at } \\
\text { Oak Ridge, safeguards and security } \\
\text { items, or emergency plan items }\end{array}$ & $\bullet$ & One system with these items \\
\hline plus & $\begin{array}{l}\text { SCI } 3 \text { items, SCI } 3 \text { - equivalent safety } \\
\text { systems and design features for safety at } \\
\text { Oak Ridge, safeguards and security } \\
\text { items, or emergency plan items } \\
\text { Environmental protection items }{ }^{4}\end{array}$ & plus & $\begin{array}{l}\text { One system with these items } \\
\text { One system with these items }\end{array}$ \\
\hline • & Environmental protection items ${ }^{3}$ & - & One system with these items \\
\hline
\end{tabular}

${ }^{3}$ Environmental protection configuration items are the items required by the environmental laws identified in Section 3.2 .

Thid.

SIbid. 
Table 3.4-2

HORIZONTAL ASSESSMENTS

\begin{tabular}{|c|c|}
\hline The operational unit has configuration items: & Horizontal assessments are recommended on: \\
\hline $\begin{array}{l}\text { SCI } 1 \text { or } 2 \text { (Oak Ridge Sites) } \\
\text { Safety systems or design features for safety } \\
\text { Item(s) required by RCRA, CAA, TSCA or } \\
\text { NPDES permits for routine effluent and } \\
\text { discharges to the environment }\end{array}$ & $\begin{array}{l}\text { Change control process, plus } \\
\text { One other function or activity such as: } \\
\text { document control, } \\
\text {. } \\
\text {. } \quad \text { drequirements documentation, } \\
\text { - } \quad \text { material condition and aging } \\
\text { management, } \\
\text { natural phenomena management, } \\
\text { - } \quad \text { fire protection, or } \\
\text {. }\end{array}$ \\
\hline $\begin{array}{l}\text { Items required by RCRA, CERCLA, TSCA, or } \\
\text { other EPA regulations to control hazardous } \\
\text { material inventories; emergency plan items; } \\
\text { SCI } 3, \text { SCI } 3 \text { - equivalent safety systems and } \\
\text { design features for safety at Oak Ridge. }\end{array}$ & Change control process only. \\
\hline
\end{tabular}

\subsubsection{4}

Assessment Team

An assessment generally should be performed by a team to gain a broad perspective and timely results (e.g., before significant changes occur to the sampled system or activity). The team as a whole should have technical competence in the operational unit, familiarity with assessment techniques, and a degree of independence. One good approach is to include team members from the operational unit and from outside the operational unit's chain of command. The team members from the operational unit bring technical competence and familiarity with the operational unit, and those not from the operational unit bring independence and objectivity.

Team selection is discussed further in Appendix A.

\subsubsection{Acceptance Standards}

Two sources that may be useful when judging the conditions observed during an assessment are:

- the performance objectives and criteria in ESS-CM-101 (ref. 2), and

- the topical discussions in the following subsections of this guidance document. 


\subsubsection{Graded Application}

Assessments are graded to reflect the risk posed by the operational unit to safety, the environment, and other considerations management may have. Table 3.4-3 provides some ideas of how grading can be accomplished. In this table the left column lists a topic related to the initial assessment, and the second column a factor that might be tailored to the importance of the operational unit. The third and forth columns identify what might be considered the most and least conservative, respectively, treatment of each of the considerations. For example, the most conservative column might apply to a reactor facility, whereas the less conservative column might apply to a low hazard facility with no more than SCI 3 configuration items. The assessment rigor that is appropriate to each operational unit may fall between these extremes.

Table 3.4-3 should be used with caution. It is intended only to convey a concept. Its example information may not be applicable to any given situation.

The responsible manager should determine the appropriate rigor for his operational unit and build it into the assessment plan. The site $\mathrm{CM}$ coordinator should concur.

Table 3.4-3

\section{EXAMPLE OF ASSESSMENT GRADING}

\begin{tabular}{|l|l|l|l|}
\hline Topic & \multicolumn{1}{|c|}{ Consideration } & \multicolumn{1}{|c|}{$\begin{array}{c}\text { Most Conservative } \\
\text { (e.g., SCI 1) }\end{array}$} & \multicolumn{1}{|c|}{$\begin{array}{c}\text { Less Conservative } \\
\text { (e.g., SCI 3) }\end{array}$} \\
\hline Personnel & $\begin{array}{l}\text { Independence } \\
\text { Qualification } \\
\text { Quantity }\end{array}$ & $\begin{array}{l}\text { Outsiders } \\
\text { Technical expert, } \\
\text { trained } \\
\text { Multi-discipline team }\end{array}$ & $\begin{array}{l}\text { Facility staff } \\
\text { Auditor }\end{array}$ \\
\hline Review & $\begin{array}{l}\text { Number/Type } \\
\text { Depth }\end{array}$ & $\begin{array}{l}\text { 2/vertical+2/horizontal } \\
\text { Detailed }\end{array}$ & $\begin{array}{l}\text { 1/vertical+1/horizontal } \\
\text { Moderate }\end{array}$ \\
\hline Formality & $\begin{array}{l}\text { Documentation } \\
\text { Guidelines } \\
\text { Quality Assurance } \\
\text { Corrective Action }\end{array}$ & $\begin{array}{l}\text { Report } \\
\text { Detailed } \\
\text { Extensive } \\
\text { Programmatic }+ \\
\text { details extrapolated }\end{array}$ & $\begin{array}{l}\text { Memo to files } \\
\text { Broad } \\
\text { Minimal } \\
\text { Programmatic fixes }\end{array}$ \\
\hline
\end{tabular}

\subsection{ChaNGE CONTROL}

An alteration or addition to a configuration item, whether temporary or permanent, is a change. Changes frequently occur because of revised missions, new regulations, hardware replacement, process improvements, and other reasons. Sometimes they occur unintentionally, as when an incorrect spare part is used or when a door is blocked oper, defeating the building exhaust system. 
Changes take a variety of forms. Examples include:

- modifying a system physically (e.g., replacing a globe valve with a gate valve),

- $\quad$ operating a system in a different way (e.g., changing the sequence of steps in an activity),

- changing an operating limit (e.g., a setpoint, or the number of people allowed in an area),

- adding or removing a restriction (e.g., requirements from a new order),

- changing the support or environment (e.g., different power source, or doing a task outdoors instead of indoors),

- processing different materials (e.g., increasing enrichment), and

- revising a document (e.g., "as-building" a drawing, or changing terminology in a procedure).

Most routine activities are not considered changes in the above sense. Examples include:

- most maintenance activities (e.g., a like-for-like replacement of pump seals), and

- $\quad$ operations as prescribed by approved procedures that already meet design and administrative requirements (e.g., system re-alignment of values from one acceptable mode of operation to another acceptable mode, or system testing).

These are not changes because they stay within the limits allowed by approved design and administrative requirements, do not require revision of configuration item documentation, and do not alter the physical description or functional capability of the configuration items.

Change control is $\mathrm{a}$ process used to ensure that the intended results are achieved when change is made. Successful change control means that the altered configuration meets known requirements and is accurately reflected in appropriate documents. It also helps avoid unnecessary changes and prevents unauthorized changes.

Phase II attempts to strengthen the change control process based on an assessment (section 3.4) of its current effectiveness. In Phase I, a small number of facilities were asked to verify that they had a basic form of change control in place for the most important configuration items. This process may have been informal in that it may have been broad, not used written procedures, and relied heavily on judgement.

In Phase II, improvements made in this basic process should result in a high level of confidence that we will get what we expect and want from the change. The primary improvements should be $a$ better basis for decisions, relying less on judgement, and more prescriptive procedures to ensure completeness and interface coverage. In addition, the change control process may be graded to reflect the relative importance of each system, activity, process, or configuration item to which it applies.

If the initial assessment demonstrates that the existing change control process is adequate, it should be left as it. 


\subsubsection{Change Control Process}

At the end of Phase II, a mature change control process will be in effect for each type of change at each participating operational unit. Depending on the needs of the operational unit, there may be one or more change processes. For example, the Research Reactors Division has separate procedures for handling design changes, temporary modifications, maintenance work, and so on. These procedures apply exclusively to the High Flux Isotope Reactor. On the other hand, it may be useful in many cases to develop common procedures that are applicable across a division, site, or Energy Systems. For example, utility groups may be able to use a common procedure.

The basic form of a mature change control process is outlined in Appendix B. The process is like that outlined in section 3.5 of reference 3 . Although considerable flexibility is possible, a mature change control process should have the following steps and characteristics as a minimum:

$\begin{array}{ll}\text { - } & \begin{array}{l}\text { Proposal } \\ \text { - }\end{array} \\ & \text { Deceptance } \\ \text { - } & \text { Review } \\ & \\ \text { - } & \text { Approval } \\ \text { - } & \text { Validation } \\ \text { - } & \text { Operation } \\ \text { - } & \text { Documentation }\end{array}$

The desired change is clearly defined and described; The responsible manager agrees resources should be spent on the change (or disagrees, and stops the process); Details are worked out, described, and analyzed; drawings, procedures, etc, are drafted or revised;

The change has an adequate technical review by operations, health, safety, environmental, and other affected functional areas; comments are resolved;

The responsible manager agrees to implement the change; The change is implemented (installed or placed in effect); The implemented change is checked or tested; The change is placed in use; and Documents used for important decisions are revised to reflect the as-installed change.

The most important characteristics are:

- Configuration items subject to the process it applies to are identified;

- Change mechanisms are identified;

- Unauthorized changes are prevented;

- Unnecessary changes are avoided;

- Procedures are documented and communicated;

- Responsibilities are defined, including interfaces;

- Appropriate requirements information is used for decisions;

- Adequate technical reviews by operations, health, safety, environmental, and other affected functional areas are made; and

- Documentation includes a description of the change, bases for development, analyses (including Unreviewed Safety Question Determinations), reviews, tests, approvals, document updates, and training.

Appendix B discusses the steps of the model in more depth as it applies to Phase II. Note that this process should be well developed and proceduralized for the most inportant configuration item, such as those addressed in Phase I. The items introduced in Phase II, on the other hand, should only need a basic form such as that described (under the title "Interim Change Control") in reference 3. 


\subsubsection{Graded Application}

If, as is often the case, it is impractical to have more than one change control process for a single facility, activity, process, or experiment, the one process should be designed to be adequate for the most important configuration items. The application of the process can then be graded to use less rigor on less important items. Table 3.5-1 provides some ideas on how change control can be applied in a graded manner. In this table the left column lists a step of the change control process (see above), and the second column a factor that might be tailored. The third and forth columns identify what might be considered the most and least conservative, respectively, treatment of each of the considerations.

Table 3.5-1 is intended only to convey a concept. It is example information may not be applicable to any given situation.

The responsible manager should determine the appropriate rigor for his operational unit and build it into the change control procedure. For operational units posing a comparatively low risk -- those not included in Phase I -- it is sufficient to maintain a simple change control process such as discussed in reference 3.

\subsubsection{Change Control Assessment Guidance}

The initial assessment process (section 3.4) looks at completeness of the change control process, and at its results. A model, such as the one discussed above, should be used to look at process completeness. The performance of the change control process may be assessed by:

- reviewing policies and procedures and interviewing managers to determine their expectations;

- interviewing experienced operations, maintenance, and test personnel to see what problems or work-arounds they face;

- walking-through facilities looking for undocumented or long-standing temporary changes;

- reviewing documents to see that recent hardware changes have been incorporated;

- reviewing corrective action reports and audit reports; and

- observing work in progress to spot field changes. 
Table 3.5-1

\section{CHANGE CONTROL GRADING}

\begin{tabular}{|c|c|c|c|}
\hline Step & Consideration & $\begin{array}{l}\text { Most Conservative } \\
\text { (c.g., SCI } 1, \text { complex system) }\end{array}$ & $\begin{array}{l}\text { Leas Conservative } \\
\text { (e.g., SCl 3, simple system) }\end{array}$ \\
\hline Proposal & Scope & All considered & All considered \\
\hline Acceptence & $\begin{array}{l}\text { Who accepts (level) } \\
\text { Acceptance Criteria }\end{array}$ & $\begin{array}{l}\text { DOE-Headquarters } \\
\text { Significant improvement }\end{array}$ & $\begin{array}{l}\text { System Engineor } \\
\text { Moderate improvement }\end{array}$ \\
\hline \multirow{3}{*}{$\begin{array}{l}\text { Development } \\
\text { Procedures } \\
\text { Requirements }\end{array}$} & Analysis rigor & $\begin{array}{l}\text { Formal Probabilistic } \\
\text { Risk Assessment }\end{array}$ & $\begin{array}{l}\text { "Back of envolope" } \\
\text { calculation }\end{array}$ \\
\hline & Steps reflecting this table & Detailed formal procedure & Less detailed procedure \\
\hline & $\begin{array}{l}\text { Sources to research } \\
\text { Rocovery noodod }\end{array}$ & $\begin{array}{l}\text { A vailable + archive } \\
\text { Pertinent information }\end{array}$ & $\begin{array}{l}\text { Available } \\
\text { Minimal }\end{array}$ \\
\hline Outputs & Quantity/nature & Extensive/thorough & Minimal/basic \\
\hline Reviow & $\begin{array}{l}\text { Who involved } \\
\text { Rigor } \\
\text { Documentation } \\
\text { Resolution }\end{array}$ & $\begin{array}{l}\text { Operations, health, safety, } \\
\text { environmental and other } \\
\text { affected functional areas } \\
\text { Detailed, calculations } \\
\text { Formal checklist \& basis } \\
\text { Documented item by } \\
\text { item }\end{array}$ & $\begin{array}{l}\text { Selected functional areas } \\
\text { Oversight review } \\
\text { Informal written or verbal } \\
\text { Sign off only }\end{array}$ \\
\hline Approval & $\begin{array}{l}\text { Who (level) approves } \\
\text { Who concurs }\end{array}$ & $\begin{array}{l}\text { DOE/Design Authority } \\
\text { /Operations managers } \\
\text { Affocted functional areas }\end{array}$ & $\begin{array}{l}\text { System Engineer } \\
\text { Operations Manager }\end{array}$ \\
\hline Implementation & $\begin{array}{l}\text { Quality Control/Quality } \\
\text { Assurance } \\
\text { Qualifications } \\
\text { Time/Condition restrict. }\end{array}$ & $\begin{array}{l}\text { Extensive } \\
\text { Certified personnel } \\
\text { Shutdown }\end{array}$ & $\begin{array}{l}\text { Minimal } \\
\text { Facility staff } \\
\text { On-line }\end{array}$ \\
\hline \multirow{2}{*}{$\begin{array}{l}\text { Field Change } \\
\text { Validation }\end{array}$} & Who approves & Same as original approval & Same as original approval \\
\hline & $\begin{array}{l}\text { Test/inspection rigor } \\
\text { Operational Readiness Review }\end{array}$ & $\begin{array}{l}\text { Key parameters } \\
\text { Extensive }\end{array}$ & $\begin{array}{l}\text { Basic smoke test } \\
\text { Minimal }\end{array}$ \\
\hline Procurement & $\begin{array}{l}\text { Who specifies } \\
\text { Standards } \\
\text { Quality Control/Quality } \\
\text { Assurance } \\
\text { Vendor qualification }\end{array}$ & $\begin{array}{l}\text { Design Engineer } \\
\text { Industry Codes } \\
\text { Extensive } \\
\text { Required }\end{array}$ & $\begin{array}{l}\text { Craftsman } \\
\text { Not required } \\
\text { Minimal } \\
\text { Not required }\end{array}$ \\
\hline Operation & $\begin{array}{l}\text { Technical Safety } \\
\text { Requirements (TSRs) } \\
\text { Training }\end{array}$ & $\begin{array}{l}\text { Comply and update } \\
\text { Formal re-qualification }\end{array}$ & $\begin{array}{l}\text { Comply } \\
\text { Informal }\end{array}$ \\
\hline Document update & $\begin{array}{l}\text { Timing } \\
\text { Quantity } \\
\text { Accuracy }\end{array}$ & $\begin{array}{l}\text { Prior to operation } \\
\text { Affected documents } \\
\text { Formal as-built }\end{array}$ & $\begin{array}{l}\text { Await periodic update } \\
\text { Fow key documents } \\
\text { Markup only }\end{array}$ \\
\hline
\end{tabular}


Material condition and aging (MCA) management is related to change control and ongoing assessments. Factors such as time, environmental conditions (e.g. high temperatures), and wear can change systems, structures, and components enough that they no longer work correctly. For example, these factors can lead to leaking roofs, leaking valves, inadequate flow from pumps, and wiring with unsafe insulation. The purpose of material condition and aging management is to detect when an important system, structure, or component can no longer function as needed, and then to repair or replace it. Detection is usually by periodic tests or inspections.

Phase II will implement or confirm material condition and aging management for the configuration items addressed originally in Phase I: SCI $1 \& 2$, the most important safety systems and design features for safety, and the most important environmental permit items. (The items added in Phase II can be addressed in Phase III.) Within the group to be addressed, the configuration items that should be monitored meet two conditions:

- the consequence of degradation or failure is unacceptable, and

- undetected failure is plausible.

Based on these conditions, monitoring might be required for a criticality alarm system, but not for a failsafe stack monitor.

\subsubsection{Monitoring Setup}

Programs are already in place to monitor and repair or replace many important systems, structures, and components. For example, monitoring and repair programs are run by $\mathrm{Y}-12$ 's Maintenance and Quality Divisions. There are also newer programs such as the Capital Assets Management Process, being implemented by site maintenance divisions.

Configuration management should take advantage of these programs where possible. To do so, the responsible manager should consider the following steps:

- identify the configuration item to be monitored;

- identify potential failure mechanisms (For example: pipe break, fire, or relief valve setpoint drift);

- identify the parameters whose degradation could lead to the failure mechanism (For example: wall thinning may lead to pipe break, deteriorated motor insulation may lead to fire. Do not include parameters unlikely to change, such as tank size or material.);

- determine the "break point" for each parameter whose degradation could lead to failure (For example: 0.2 inch wall thickness, or $80 \mathrm{gpm}$ flow rate);

- determine if existing monitoring programs:

- include each configuration item,

- monitor each parameter whose degradation could lead to failure, and

- repair or replece the configuration item prior to its "break point;" and

- supplement the existing programs as needed to include the appropriate configuration item and associated parameters.

Assistance from Facility Safety and engineering may be needed, especially for the first four steps. 
Alternately, the operational unit's staff may want to do its own monitoring for some items. This could be desirable when, for example, operator rounds provide adequate monitoring of items such as filters.

\subsubsection{Graded Application}

The application of material condition and aging management should be graded. Table 3.6-1 provides some ideas for one way grading can be accomplished. In this table, the first column lists various material condition and aging management topics. The second column lists considerations that might be tailored for the topic. The third and forth columns identify what might be considered for the configuration items needing the most and least conservative treatment, respectively.

Table 3.6-1 is intended only to convey a concept. Its example information may not be applicable to any particular situation.

\subsubsection{Material Condition and Aging Management Assessment Guidance}

The initial assessment process (section 3.4) should confirm the SCI 1 and 2, safety systems and design features for safety, and environmental protection items are appropriately monitored for the sample system. The assessment may be conducted by:

- $\quad$ reviewing records held by the monitoring or operating staff;

- discussions with engineering, operations, and test and inspection personnel;

- walkdowns; and

- observing tests and inspections.

Table 3.6-1

MCA MANAGEMENT GRADING

\begin{tabular}{|l|l|l|l|}
\hline Topic & \multicolumn{1}{|c|}{ Consideration } & \multicolumn{1}{|c|}{$\begin{array}{c}\text { Most Conservative } \\
\text { (e.g., SCI 1, items most } \\
\text { likely to degrade) }\end{array}$} & $\begin{array}{l}\text { Less Conservative } \\
\text { (e.g., SCI 3, items least } \\
\text { likely to degrade) }\end{array}$ \\
\hline \hline Scope & $\begin{array}{l}\text { Structures, Systems, } \\
\text { Components } \\
\text { Design Parameters }\end{array}$ & $\begin{array}{l}\text { Those subject to } \\
\text { degradation } \\
\text { Those that can degrade }\end{array}$ & Sample \\
Monitoring & $\begin{array}{l}\text { Frequency significant few } \\
\text { Number of parameters } \\
\text { Trending } \\
\text { Documentation } \\
\text { Quality Control } \\
\text { /Quality Assurance }\end{array}$ & $\begin{array}{l}\text { Often } \\
\text { Many } \\
\text { Required } \\
\text { Report } \\
\text { Detailed review }\end{array}$ & $\begin{array}{l}\text { Seldom } \\
\text { Few } \\
\text { Optional } \\
\text { Test Engineer's notes } \\
\text { Sample basis }\end{array}$ \\
\hline Corrective Action & $\begin{array}{l}\text { Margin } \\
\text { Time }\end{array}$ & $\begin{array}{l}\text { Significant } \\
\text { Well before likely failure }\end{array}$ & $\begin{array}{l}\text { Small } \\
\text { Before likely failure }\end{array}$ \\
\hline
\end{tabular}




\subsection{DOCUMENT CONTROL}

For configuration management purposes, documents may be paper media (e.g., correspondence, drawings, procedures, datasheets), photo media (e.g. microfiche), or electronic media (e.g. computer databases). Records are included.

Document control is a process to ensure documents used in making important decisions are accurate. That is, making sure that such documents, including operating procedures and selected engineering drawings, accurately reflect both the requirements and the physical and functional configuration of configuration items, including installed changes. This is important because inaccurate information can lead to serious mistakes in operations, maintenance, training, modifications, procurement, evaluations, and planning.

The Phase I document control effort (ref. 3) was limited to confirming or providing minimal document control to those few documents that are most important to safety and the environment. These included safety analyses, environmental permits, and selected drawings and procedures. Emphasis was placed on identifying these and keeping them current if changes were made to the associated equipment or activity.

Phase II will seek to focus more on other documents (e.g. operating procedures, drawings, and specifications) used for decisions affecting health, safety, and the environment. An objective of Phase II will be to bring these documents up to date with complete current information, and to ensure an adequate process exists to keep them current as new information is found (see section 3.8) or as changes are made to the configuration items (see section 3.5)

Phase II is not expected to create new document control processes. It may cause improvements in existing processes based on the initial assessment (section 3.4). The assessment process should identify any weaknesses in the existing document control process or its use.

\subsubsection{Documents for Phase II Control}

In Phase II, specific documents (including drawings) that are used for decisions, and thus need control, should be identified for each configuration item or group of configuration items. "Unchangeable" documents such as orders or industry standards are not included. The list of documents should, as a rule, be kept small. It should include documents that are likely to be used in activities such as normal and offnormal operation, modifications, maintenance and procurement, testing and inspection, safety evaluation, emergency planning, and other activities affecting health, safety, and the environment. In most cases it need not include documents that are not used for decisions, such as administrative procedures, some construction drawings for an operating facility, and some records. Examples of types of documents that should be considered for control are listed in Appendix C.

Some documents on the list must be controlled for any operational unit. These include many of the "source" documents in Appendix C. The source documents are binding commitments to external authorities. Selection of the others should be made specifically for each operational unit based on input from sources such as the following:

- operating, maintenance, test and inspection, and other "hands on" personnel;

- management personnel for the operational unit; 
- the design authority;

- $\quad$ key support groups such as procurement, training, emergency management, security;

- facility safety and environmental management organizations; and

- $\quad$ findings of the initial assessment.

\subsubsection{Document Control Process}

For most Phase II documents, the document control systems currently existing at each site should be used. Use of these systems will take advantage of the experience they are built on and will prevent unnecessary duplication.

Note, however, that some existing document control systems are not yet full scope. For example, some do not handle drawings, which may be maintaine' $y$ engineering. Such arrangements have lead to cases in which operations personnel have kept their own, unofficial versions of drawings that conflict with the approved versions. In such a case, the document control system may need to be modified to more fully support the operational unit's needs, or a more responsive parallel control system established.

There may be cases in which immediate use of existing document control systems is not desirable, such as for documents being updated or for temporary documents. In these cases, document control should be set up to along the lines outlined in Appendix C. Assistance can be obtained from Information Management Services or a site document control group like K-25's Procedures and Records Management organization.

\subsubsection{Document Updating}

It is likely that drawings and other documents will need to be revised or created during Phase II. Revisions to existing documents may be needed if they do not accurately reflect field conditions or if new information is developed. For example, an electrical wiring diagram may be found to not show the wiring connections as they actually exist inside a cabinet. A new document may created for a newly-defined use, as when drawings originally provided by engineering do not fill an operating division needs for a simplified, consolidated information.

The document creation or updating process should follow these general steps:

- Establish the document scope and purpose. Consider the end needs of the user and the scope of existing or planned documents.

- Set priorities. Start with documents most important to safety, health, and the environment.

- Do research. For drawings, procedures, and many other documents, a walkdown should be performed. Establish criteria for the walkdown/research in advance. These criteria should ensure that the finished product will have the detail and precision required by the end user.

- Make draft or markup. This may be done during the walkdown or research.

- Review the draft.

- Have affected organizations--the user, the design authority, utilities, fire and security, and others--review the document to see that it meets their needs and is accurate as tar as they know, or to identify conflicts with their information. 
- Evaluate conflicts between the draft, which should represent actual conditions, and other important documents An Unreviewed Safety Question Determination may be required.

- Do an independent walkdown.

- Incorporate corrections and issue. Organizations whose functions are affected should concur.

- Place in document control process.

New or revised documents should be scheduled according to the priorities and resources of the operational unit. However, while the new or revised documents are being prepared, the operational unit should have in place some process to assure that documents used for important decisions are as accurate as possible. One method for doing this is:

- $\quad$ "red-line" a master set of documents,

- limit access to (maybe lock up) the masters,

- prevent use of documents other than current, dated copies of the master, and

- keep the masters current by having changes concurred in by the person keeping the masters (such as responsible manager, shift supervisor, or control room operator).

Another important consideration for updating documents is to ensure changes are coordinated with other affected documents and appropriately processed. For example, a change to a flow diagram should be reflected in safety analyses, maintenance procedures, procurement specifications, operating procedures, and training materials. Processing of changes should be reviewed by those people who would review a change to the configuration item. For example, a drawing should not be revised to reflect field conditions of a radioactive waste system unless a safety analysis and Unreviewed Safety Question Determination are completed. In other words, a document should not be assumed to be wrong when it disagrees with the field or another document: the document may be the only thing that is correct.

\subsubsection{Graded Application}

The primary document control process grading is in the number and type of documents controlled. This will vary with the importance, complexity, and nature of the configuration item. For example, a SCI 2 piping system would be expected to have more documents; such as calculations and equipment performance records, than a similar SCI 3 system. In this case, the difference in number and type of documents reflects the need for more information (both current and historical) to support confidence in the safe operation of the system with greater potential failure consequences. Appendix $\mathrm{C}$ suggests some types of documents that could be useful for the more and less important Phase II configuration items.

Document control can also be graded to some extent by selection of the document control system. The extremes are:

- most conservative--use a good existing site/organization document control system; or

- less conservative--lock the documents in a locally-controlled file cabinet.

Use of good existing processes is generally more conservative because it provides storage, marking, updating, distribution, and other features. Documents important to health, safety, and the environment should be controlled in this manner. There $m$ ay be situations in which the less conservative process is adequate. For example, as long as applicable laws, regulations, orders, and company requirements are 
met, locking the only copy of a document in a desk may be adequate for background materials that are temporary and/or are used by only one person or small group. In either case, the intent of the guidelines of Appendix C should be met.

\subsubsection{Document Control Assessment Guidance}

The initial assessment (section 3.4 ) should confirm that:

- a document control system is in place that:

- meets the basic guidelines discussed in Appendix C,

- is reasonably efficient (so that it is not bypassed);

- documents important to decisions affecting health, safety, or environmental protection are accurate, clearly identified, and controlled;

- documents important to decisions affecting health, safety, or environmental protection are readily available to and used by those people making decisions; and

- uncontrolled documents are not used for decisions affecting health, safety, or environmental protection.

The above points should initially be determined based on the vertical assessment of a system, and the horizontal assessment of change control. If a horizontal assessment of document control is made, it may be conducted by:

- walking through facilities to spot uncontrolled documents,

- comparing sample sets of documents for consistency,

- reviewing a set of potentially-affected documents to see if recent hardware or procedure changes have been incorporated,

- observing work in progress to spot use of uncontrolled documents, and

- $\quad$ taking a sample set of controlled documents to the field to see if they are accurate.

\subsection{INFORMATION BASE}

The information base is the information that is used to make decisions. It provides a basis for safe, reliable, and efficient activities such as change control. The information that is needed for configuration management includes:

- what are the important features of the operational unit (the configuration items),

- what must the configuration item do (design and administrative requirements), and why (bases),

- what exists now (physical and functional configuration),

- what documents contain essential information (configuration item documents), and

- what are the appropriate change and document control processes?

Table 3.8-1 provides examples of types of information that may be useful for configuration management purposes.

In Phase I, information needs were limited to what was needed to support sound judgements about the most significant safety and environmental questions. Safety analyses and environmental permits were 
the basis, although other readily available documents (e.g. red-lined drawings) and current personnel could supplement this information.

In Phase II, the information base will still primarily be the safety analysis and environmental permits. Facility safety information will be expanded by analyses performed in the ongoing Safety Analysis Report Update/Upgrade Programs. In addition, other information, such as design requirements that are in engineering project files, will be recovered.

\subsubsection{Requirements}

Requirements are the functions, specified parameters, and conditions that a configuration item must satisfy, plus the constraints it must function within. The two general types of requirements are design and administrative. Behind each requirement there is a basis that explains why the requirement is as stated. These requirements and design bases are discussed below.

\subsubsection{Design Requirements}

Design requirements are the outputs of the design process that specify the parameters that a configuration item must meet to do its job. Examples of such parameters are:

- maximum, minimum, and normal pressure the component should work in (e.g., fire pump capable of providing water with atmospheric pressurc on its suction and 200 psi on its discharge);

- maximum, minimum, and normal temperature (e.g., electronics to operate correctly in $40-100 \mathrm{~F}$, with normal at $60 \mathrm{~F}$ );

- voltage (e.g., motor to operate on $480 \mathrm{v}$ );

- seismic resistance (e.g., building to not collapse in severe earthquake)

- type of component (e.g., 1/2" globe valve); and

- $\quad$ arrangement (e.g., pressure gauge must be more than 10 pipe diameters beyond pump discharge)

It is important to distinguish the design requirements that must be known, those that would be nice to know, and those that are not necessary. Examples might include, respectively: the load capacity of a transformer, the load-bearing capacity of an office building, and the size of a maintenance drain plug. For Phase II, only requirements essential to safety (as identified in safety analyses) and environmental protection (as identified in environmental permits/commitments) must be known. In the event design requirements are needed beyond these, they are generally found in engineering drawings, calculations, and specifications for the original design and subsequent modifications. Sometimes they are not recorded or cannot be found. If necessary, recovery of missing information may be performed as discussed below.

\subsubsection{Design Bases}

Design requirements are derived from design bases through the design process. Design bases explain why a design requirement exists. For example, the design basis for an electrical distribution system includes the expected system loads, cable routing and calculations from engineering drawings and analyses, and industry codes and standards. 
Table 3.8-1

EXAMPLES OF INFORMATION

\begin{tabular}{|c|c|}
\hline Category & Information \\
\hline Bases & $\begin{array}{l}\text { Safety requirements from current safety analyses, TSRs, USQDs } \\
\text { Limits (e.g. tank level, or number of drums stacked) } \\
\text { Performance requirements from environmental permits and authorization basis } \\
\text { Procedural requirements for operations, maintenance, testing and inspection, } \\
\text { criticality safety, others } \\
\text { Sources (document/person) of requirements } \\
\text { What assumptions the designer/author made that, if not valid, would fail the } \\
\text { configuration item (e.g. all doors must remain closed for ventilation system to } \\
\text { work) } \\
\text { What the item handles }\end{array}$ \\
\hline $\begin{array}{l}\text { Design } \\
\text { Requirements }\end{array}$ & $\begin{array}{l}\text { Design parameters that are essential to doing this job: } \\
\text { - size } \\
\text { - temperature limits (e.g. } 104 \mathrm{~F} \mathrm{max}) \\
\text { - flow rate (e.g. } 200 \mathrm{gpm}) \\
\text { - operating pressure (e.g. } 100-200 \text { psia) } \\
\text { - environmental conditions (e.g. temperature, humidity) } \\
\text { - power requirements (e.g. amperage, voltage) } \\
\text { - cooling load (e.g. } 300 \mathrm{BTU} / \mathrm{hr}) \\
\text { - weight, center of gravity } \\
\text { - material (e.g. bearing corrosion resistance) } \\
\text { - component type (e.g. globe valve) } \\
\text { - vibration limits } \\
\text { - lubricants } \\
\text { - start/stop times } \\
\text { - design life } \\
\text { - interface requirements (e.g. size, material, air pressure) } \\
\text { Interfacing/interacting systems/activities (e.g. equipment cooled by the } \\
\text { ventilation system) } \\
\text { Applicable industry/government codes and standards } \\
\text { What the designer/author had in mind (e.g. why he used a centrifugal instead of } \\
\text { a positive displacement pump) }\end{array}$ \\
\hline $\begin{array}{l}\text { Operating } \\
\text { Conditions \& } \\
\text { Restraints }\end{array}$ & $\begin{array}{l}\text { Conditions that must be observed in order for the configuration item to do its } \\
\text { job (e.g. temperature must be above freezing) } \\
\text { What testing/inspection is needed (e.g., vibration monitoring) } \\
\text { What support systems (e.g. room coolers) must be in place and functioning } \\
\text { Maintenance requirements to keep equipment running } \\
\text { Test and inspection requirements } \\
\text { Surveillance requirements } \\
\text { Operational restrictions (TSRs) }\end{array}$ \\
\hline
\end{tabular}

(Table continued) 
Table 3.8-1

\section{EXAMPLES OF INFORMATION (continued)}

\begin{tabular}{|l|l|}
\hline Existing Situation & $\begin{array}{l}\text { What the item looks like (current physical configuration) } \\
\text { What the item should look like (intended physical configuration) } \\
\text { Why the item should look that way (basis) } \\
\text { What the item should do (intended functional configuration) } \\
\text { Why the item should work that way (basis) } \\
\text { How the item should work (functional configuration) } \\
\text { What results should we see if things work as intended }\end{array}$ \\
\hline $\begin{array}{l}\text { Performance } \\
\text { Experience }\end{array}$ & $\begin{array}{l}\text { Equipment age (or installation date) and condition (e.g. badly worn) } \\
\text { Past performance: test results, failure and maintenance record } \\
\text { Past performance at other locations } \\
\text { Past modifications: what, why, and who } \\
\text { Vendor recalls/service bulletins } \\
\text { Mean time to failure, mean time to repair }\end{array}$ \\
\hline Procurement & $\begin{array}{l}\text { Procurement specifications } \\
\text { Part numbers } \\
\text { Where similar equipment is in use } \\
\text { Vendor data and recommendations }\end{array}$ \\
\hline Responsibilities & $\begin{array}{l}\text { Who "owns" the item } \\
\text { Who must approve and make changes } \\
\text { Who the design authority is }\end{array}$ \\
\hline Documents & $\begin{array}{l}\text { Associated documents/databases } \\
\text { Training materials }\end{array}$ \\
\hline
\end{tabular}

Knowing the design bases behind a design requirement is important if and when we wish to change the requirement. That is, if we have an environmental permit requirement to not fill a tank more than 60 percent, we do not necessarily need to know why - just do what it says. However, if we want to increase the allowable to 65 percent, we have to be able to prove this is acceptable. To do so, we have to know why the 60 percent was imposed.

In general, design bases should not be recovered or re-created unless and until needed. The safety analyses report update/upgrade programs and the analyses supporting environmental permits are adequate for most operational units during Phase II.

\subsubsection{Administrative Requirements}

Administrative requirements are restraints placed on people. For configuration management purposes, the only administrative restraints of interest are technical in nature. That is, ones that control an activity whose failure could result in unacceptable consequences to health and safety, environmental compliance, and other objectives as identified in Energy Systems policy ES-CM-100 (ref. 1). Examples include: 
- frequency of environmental monitoring,

- accuracy of chemical analysis,

- $\quad$ spacing on stored drums of radioactive waste, and

- type of weapons allowed in certain areas.

The easiest way to think of the administrative requirements may be to look upon the person as fulfilling a role that a machine could do. For example, either a machine or a person can be used to take samples of effluent. With this in mind, think of the administrative requirement as equivalent to the design requirements for a machine doing the same job. If the machine would qualify as a configuration item, then the administrative requirement is probably important; if not, then the administrative requirement is probably not of interest.

Administrative requirements are generally found in safety analyses, Technical Safety Requirements, environmental permits, operating procedures, and training. They may also be found in engineering documents (as stated or implied assumptions).

\subsubsection{Information Recovery}

Design requirements information that is needed during Phase II comes largely from safety analyses, environmental permits/commitments, researching readily available documents (e.g., drawings and maintenance procedures), and interviewing current personnel. In the event additional information is needed, information recovery or re-creation (together, called reconstitution) may be necessary.

Information recovery means finding information that still exists, but may be in files (e.g., design packages) or people's minds. Re-creation means actually re-doing the analyses or other design work and producing the new data. Due to the expense, re-creation is generally reserved for situations when the information is essential and cannot be reasonably recovered otherwise. Recreation may be used in lieu of recovery when it is advantageous to do so.

In general, information recovery beyond what is done in the Safety Analysis Report Update/Upgrade Programs should be very limited. If additional information is needed, recovery activities should only be carried out for SCI 1 and 2 , and selected safety systems and design features for safety. Re-creation activities for SCI 1 items will generally be done in Phase III if needed. Recovery activities for the remaining items will be done in Phase III as needed.

In the event additional information on requirements is needed, the following steps should be followed. Although the last two steps apply to any effort, the above guidance should be used to determine how far down the remaining list to go for each type of configuration item.

- Identify the required information -- design parameters, administrative constraints and limits.

- Identify possible/probable sources -- records, people, tests.

- Research available documents for readily found recorded information .- safety analyses, environmental permits, procedures, drawings.

- Interview current personnel for unrecorded information -- operators, engineers, test personnel. 
- Identify missing information, and evaluate how important it is .- vital to safe and efficient operation, goud to know, or probably not useful.

- Research files/archives for recorded information -- design projects, operations logs, maintenance records.

- Interview former personnel, when practical, for what they know ... retired or changed jobs, consultants, subcontractors (should be done as early as practical to capture as much information as possible before they forget it, become harder to reach, or die).

- Reconcile conflicts (expected with information from different sources) -- one source says must be longer than one foot, while another source says must not be longer than one foot.

- Document the information and make it available to those who need it -- use controlled documents.

\subsubsection{Current Configuration}

Information on the current configuration is determined by a walkdown. That is, look, measure, and test. Confirm or correct (using appropriate procedures) appropriate documentation, such as drawings, to reflect the actual arrangement of equipment, storage containers, dikes, or other items of interest. Tie these documents into the change control procedure so that future field changes will be reflected.

\subsubsection{Graded Application}

The information needed for configuration management activities varies with the complexity of the situation and the importance of configuration items involved. Less is needed to understand a dike than a reactor's reactivity control system. Information requirements for each configuration item can be established on a case basis using the guidance discussed above.

Considerations for how much information is needed include:

- importance of the configuration item to safety (e.g., SCI 1 over SCI 3),

- importance of the configuration item to environmental protection (e.g., protecting against a large spill over avoiding a fine),

- consequence of not having information readily available (e.g. shutdown over delay in implementing mission change), and

- difficulty understanding configuration item (e.g. electronic controller over power distribution system.

Table 3.8-2 provides some ideas of one way grading can be accomplished. It is based on the idea of effort: how hard do we try to find information? It suggests types of information that are likely to be needed for various types of configuration items. Table 3.8-2 is intended only to convey a concept. It may not be applicable to any particular situation. 


\subsubsection{Information Assessment Guidance}

The initial assessment (Sect. 3.4) will look at the completeness and accuracy of the information available on the sample system. Emphasis should be on documented information. The assessment should verify:

- design and administrative requirements are known;

- design requirements accurately reflect applicable design bases;

- there are no significant conflicts or ambiguities;

- field conditions are accurately reflected in the safety analysis report, operational drawings, and other records;

- applicable requirements and actual field conditions are appropriately reflected in procedures, training materials, maintenance procedures, vendor manuals, and other instructions; and

- information that may used for decisions is recorded on controlled documents. (see Sect.3.7)

Note that missing requirements and their bases may have to be recovered for the sample system or activity prior to performing the initial assessment. Some of this information may turn out later to not be needed for the system. For example, the design basis for a system may have to be recovered to assess whether or not the design requirements are adequate, but then will not be needed for continued operation.

Table 3.8-2

\section{INFORMATION GRADING}

\begin{tabular}{|l|l|l|}
\hline \multicolumn{1}{|c|}{ Information } & \multicolumn{1}{|c|}{$\begin{array}{c}\text { More Important CI } \\
(\text { e.g., SCI 1) }\end{array}$} & \multicolumn{1}{|c|}{$\begin{array}{c}\text { Less Important CI } \\
\text { (e.g., SCI 3) }\end{array}$} \\
\hline Safety Basis & $\begin{array}{l}\text { From safety analyses and } \\
\text { Technical Safety Requirements }\end{array}$ & From safety analyses \\
\hline Environmental Basis & $\begin{array}{l}\text { From environmental permits } \\
\text { and other commitments }\end{array}$ & $\begin{array}{l}\text { From environmental permits } \\
\text { and other commitments }\end{array}$ \\
\hline $\begin{array}{l}\text { Administrative Requirements } \\
\text { (required to support safety or } \\
\text { environmental protection) }\end{array}$ & $\begin{array}{l}\text { From available documents, } \\
\text { current personnel, files, and } \\
\text { former personnel }\end{array}$ & $\begin{array}{l}\text { From available documents and } \\
\text { current personnel }\end{array}$ \\
\hline $\begin{array}{l}\text { Design Requirements (required } \\
\text { to support safety or } \\
\text { environmental protection) }\end{array}$ & $\begin{array}{l}\text { From available documents, } \\
\text { current personnel, files, and } \\
\text { former personnel }\end{array}$ & $\begin{array}{l}\text { From available documents and } \\
\text { current personnel }\end{array}$ \\
\hline
\end{tabular}

\subsection{CONFIGURATION MANAGEMENT PROCESSES UPGRADE}

If the initial assessment demonstrates that an existing management process is adequate, the process should not be changed. 
The initial assessment may point out weaknesses in management processes such as procurement or procedure control. These weaknesses could be demonstrated by inconsistencies among the identified requirements, actual arrangement and operational capability, and documentation of configuration items reviewed in the assessment. For example, if the assessment finds that changes to some environmental permit items have not been sent to the regulator as required, the review and approval aspect of the change control process might need to be strengthened. If modifications to a fire protection system have been made without updating drawings, then the process for updating configuration item documentation could need to be improved.

Process weaknesses can be pinpointed by studying the related procedures or instructions and training. Corrective action might include upgrading procedures and giving related training.

As an alternative to upgrading existing management processes, there may be situations in which it is more practical to switch to an existing, proven process. For example, if the assessment shows that procedures are not controlled adequately to ensure operators have current information, the solution may be to simply place all procedures in an established document control system at the site.

It is often important not to make changes in a process without a careful examination of the problem. Although the assessment may indicate a problem, it may not provide enough information to develop corrective action. It is generally best to investigate an indicated problem before making changes. This will improve the likelihood of fixing the problem without introducing new ones. An extra vertical assessment is one way of telling whether the first one missed something important or focused on an isolated problem.

Sections 3.5 and 3.7 provide additional guidance on what to look for in change and document control processes.

\subsection{REQUIREMENTS, CONFIGURATION, AND DOCUMENTATION UPGRADE}

For more complex operational units, the initial assessment is likely to identify some inconsistencies among requirements, physical and functional configuration, and documentation. For example, the load-bearing capability of a floor may not be known, a public address system (used for evacuations) may not be connected to standby power, or as-built drawings for buried power lines may be inaccurate. As a result, corrective action should be taken. This action might include one or more of the following:

- modification of the configuration item to meet applicable requirements (A design change package may be needed. An activity may need to be done differently requiring changes to procedures and training.) (see Sect. 3.5);

- updating key drawings and other documents or creation of new documents (see Sect. 3.7); or recovery of missing information (see Sect. 3.8).

For Phase II configuration items, most differences between the known health, safety, and environmental requirements, the as-is configuration item, and the documentation need to be resolved. If 
serious or numerous inconsistencies are indicated by the assessment, then a comprehensive review of other important configuration items is recommended to identify and correct inconsistencies. Such inconsistencies indicate that we do not know what is required, that the configuration items are not capable of performing as required, or that the documents used for decisions are inaccurate. These conditions could be unacceptable for configuration items considered important to health, safety, and the environment.

\subsection{PHASE II DOCUMENTATION}

At the end of Phase II, the operational unit's staff should document what was done. The documentation need not be elaborate, but should be sufficient for the operational unit to withstand a challenge regarding health, safety, and environmental protection. The documentation should include:

- identification of operational unit;

- list of Phase II configuration items;

- description of the assessment (e.g., team members; sample system identification; description of walkdowns, reviews, calculations, etc.; observations and findings; conclusions and recommendations); and

- summary of corrective actions completed or planned for long-term corrective action.

The information should be in enough detail to assure reviewers that the assessment and corrective action were adequate to identify and correct significant health, safety, and environmental weaknesses. The detail and quality of the documentation should demonstrate that the major health, safety, and environmental requirements are known for the operational unit, the physical and functional configuration of important features satisfy the requirements, and that documentation used for important decisions is accurate.

\subsection{DATABASES}

A large amount of information is needed for most operational units. Configuration management information needed includes, for example:

- identification and description (e.g., 1 " carbon steel globe valve in cooling water system located at room $\mathrm{X}$ in building $4500 \mathrm{~S}$ ) of each configuration item,

- responsibilities (e.g., owner, change control board, design authority),

- applicable documents (e.g., name, number, and revision of safety analyses; operating procedures; and drawings),

- design and administrative requirements (e.g., limit on level or height),

- change history of configuration item (e.g. list of change packages), and

- safeguards/security information.

Databases are used to manage the information so that it can be kept current and retrieved as needed. Energy Systems has developed the Configuration Management Information System (CMIS) that may be used for configuration management needs during Phase II. Configuration Management Information System is being upgraded with more data fields and electronic linkages to other databases, such as the 
Engineering Drawing Information System. These improvements are intended to match CMIS capabilities with basic configuration management needs for major users. This makes it unnecessary for various organizations to develop separate databases. 


\section{Appendix A}

\section{INITIAL ASSESSMENT}

The initial assessment ${ }^{\prime}$ will rely on two basic assessment approaches - horizontal and vertical. The horizontal assessments will review the implementation and effectiveness of programs or processes as they are applied throughout a operational unit to identify needed improvements. Horizontal assessments are not intended to determine the functionality of a system or a component. The vertical assessments, on the other hand, will review the available information on a sampling of systems and cut vertically across many elements (i.e., prog:ams, processes, or activities) that must work together effectively for the system to function properly. This review of multiple programs, as they apply to a single system process can provide a reasonable assurance of functionality and enhanced probability of safe and reliable performance. One objective of the vertical assessments, which is important to configuration management, is the determination of the underlying root cause(s) of identified deficiencies (e.g., the need for programmatic improvements).

\section{A.1 INITIAL VERTICAL ASSESSMENTS}

The vertical assessments will, on a system or activity basis, focus on the whether the configuration items are correctly reflected in the available documentation and satisfy the applicable requirements (design or administrative). Vertical assessments can also be effective in evaluating and identifying weaknesses in the configuration management related programs and processes. For example, it may find that the design requirements for the inspected system/activity are not adequately documented. The,corrective action may be to update the document control programs.

An initial vertical assessment would include the following basic steps:

- Select the system/activity to be assessed. It should be representative of the identified configuration items, the available documentation, and the requirements. Other selection criteria might be that it be relatively new so it will have readily available requirements and documentation. In order to detect patterns and identify programmatic problems, a vertical assessment on more than one system/activity may be needed. The larger the number, the better the sample and the more accurate the results.

- Review the available documentation containing the applicable requirements (design and/or administrative) and the design basis against the related configuration items to determine consistency, technical adequacy, and deficiencies. Pay special attention to consistency between: the assumptions made (e.g., design calculations), design outputs, and the requirements; and the design and administrative requirements against orie another and as reflected in the safety analyses, procedures, vendor material, and other sources.

\footnotetext{
${ }^{1}$ Reference 2 defines the initial assessment to include identification of configuration items. This document, however, has split that function out to clarify the overall Phase II process.
} 
- Perform walkdowns to compare the existing configuration items with the documentation and note any discrepancies. Often, these walkdowns will result in marked-up (or annotated) documents.

To minimize the impact on resources, the initial walkdowns should sample a representative cross section of configuration items within the system/activity being assessed. The sample should be large enough to ensure that a significant portion of the configuration items are reviewed.

A minimum acceptance threshold for discrepancies should be established. If the sample walkdowns indicate significant discrepancies, then the walkdown sample sizes should be increased.

- Document the inconsistencies, technical inadequacies and missing information identified as assessment concerns.

- Analyze the assessment concerns and identify any programmatic weaknesses. Fixing a specific concern without correcting the underlying programmatic deficiencies that allowed them to occur is not the objective. Final analysis of the assessment concerns can identify the underlying cause(s). For example, a discrepancy between the existing configuration item and the documentation might be due to inadequate interface between change control and document control; or differences between the design basis information and design requirements might be due to inadequacies in the design process.

- Recommend improvements to correct programmatic deficiencies and what actions to take to prevent these types of problems from occurring in the future.

\section{A.2 INITIAL HORIZONTAL ASSESSMENTS}

The initial horizontal assessment will focus on the change control or another process and assess the effectiveness of that process across many systems/activities as applied throughout the operational unit.

An initial horizontal assessment would include the following basic steps:

- Identify the process to be assessed. As a minimum, the initial horizontal assessments should look at the existing change control procese.

- Establish the assessment criteria for the program based on Appendix A of Energy Systems Standard ESS-CM-101 (ref. 2) and other appropriate sources.

- Compare the available program documentation with the established assessment criteria to identify strengths and potential weaknesses based on existing program comprehensiveness and obvious omissions.

- Perform a review in the field through interviews with knowledgeable facility personnel, additional document reviews, and observation of work in progress. The objective is to determine if the program is working. Emphasis should be on problems, not on missing program elements. Remember this should not be a compliance review but rather a performance-based review of how well the program is implemented and its effectiveness at accomplishing its objectives. This 
performance-based approach is essential to identifying the underlying causes of problems and needed program improvements.

- Compare the potential weaknesses identified during the document review step with the problems identified during the field review step to identify programmatic strengths and weaknesses.

- Recommend improvements to correct programmatic deficiencies and what actions to take to prevent these types of problems from occurring in the future. Strengths should be identified and acknowledged to ensure that resources are properly allocated for the correction of weaknesses.

- Document the programmatic strengths and weaknesses and the recommended improvement actions.

\section{A.3 CONDUCT OF ASSESSMENT}

\section{A.3.1 Assessment Plan}

A brief plan should be developed for each assessment. The plan should provide details on aspects of the assessment such as scope, objectives, schedule, duration, assessment criteria, team composition, training requirements, documentation requirements, and tracking mechanisms for discrepancies, open items and corrective actions. The plan should, as a minimum, be reviewed and approved by the team leader and responsible manager.

\section{A.3.2 Assessment Schedule and Duration}

A coordinated schedule should be established for the assessment. If possible, the assessment should be scheduled during a time when the maximum potential to evaluate performance exists and facility personnel are available to support the assessment through open interaction and dialog. The duration of the assessment should consider the type/complexity of the assessment and the size, experience and composition of the team. Typically, assessment mzy be done over a period of two to six weeks, with interruptions. The expected duration should be established prior to the assessment. Also, if the duration is too long a truly representative snapshot in time is not achieved since changes and corrective action may occur while the assessment is in progress.

\section{A.3.3 Assessment Team}

The assessment team should generally consist of a leader and several knowledgeable people from different disciplines. The team members should have no direct responsibility for developing or implementing the system or activity being assessed. They should, however, have a technical understanding of the sample system, activity, or process. For example, a moderately complex category 2 (i.e., moderate nuclear hazard) facility with an environmental permit and security requirements might use a team such as: 


\begin{tabular}{|c|c|c|}
\hline Position & Person & Function \\
\hline Core Team & Supervisor & Team Leader; management processes experience \\
\hline Core Team & System Engineer(s) & Technical understanding \\
\hline Core Team & Operations & Operating \\
\hline Core Team & Maintenance & Maintenance \\
\hline Part Time & Health Physics & Radiological protection \\
\hline Part Time & Security & Security barriers, classified materials \\
\hline Part Time & Fire Protection & Fire protection \\
\hline Part Time & Document Control & Documentation handling \\
\hline Consulting & Facility Safety & $\begin{array}{l}\text { Safety requirements interpretation; identification of } \\
\text { items }\end{array}$ \\
\hline Consulting & $\begin{array}{l}\text { Environmental } \\
\text { Management }\end{array}$ & $\begin{array}{l}\text { Environmental requirements interpretation; } \\
\text { identification of items }\end{array}$ \\
\hline Consulting & Engineering & System design requirements, drawings \\
\hline
\end{tabular}

In these roles, the core members stay together for the duration of the assessment and are responsible for its ultimate outcome. The part time members come in for a limited time (e.g., 3 days at mid-point) to look at specific topics. They train and meet with the core team. The consultants are brought in for specific issues. They need not train or meet with the team regularly.

The exact size and composition of the team should consider the complexity of the operational unit being assessed. For example, a simple waste storage area or a carpenters shop with one environmental permit may be done by one or two people.

Team members should understand the assessment process and be able to communicate concerns effectively. Familiarization can come from the team leader, based on this or similar guidance. Formal training (not recommended for most operational units) can be obtained from the Energy Systems Evaluation Group.

\section{A.3.4 Assessment Criteria}

The performance objective and criteria in ESS-CM-101 (Ref. 2) should be adapted for the assessment. The program, process or activity will be measured against these. The criteria may be modified according to the type of assessment and the area to be assessed.

\section{A.3.5 Assessment Methods}

During the assessment, information may be obtained through the proven techniques of interviews, document reviews, and observations. Each technique provides a different perspective or type of information and, only when used in combination, can the entire situation be assessed. No one technique should take precedence over another. See below for further discussion on these techniques. 


\section{A.3.6 Assessment Meetings}

The following is a recommended list of meetings to be considered during an assessment.

- Initial Team Meeting

During the initial team meeting, the team leader will brief the team members on the scope, schedule, methodology, assignments, and objectives of the assessment. This meeting should be held on the first day of the assessment and prior to any formal entrance meeting.

- Daily Team Meetings

To promote team synergy, a daily team meeting should be held during the assessment. The success of the assessment will be greatly enhanced as team synergy is established and as team members interact to benefit from the experience and efforts of the other team members. During the daily meting, each team member is expected to summarize the results of the days' activities, provide information pertinent to the assessment, and discuss potential concerns and issues. Questions, interjections and comments from the other team members from various perspectives will be encouraged and expected. If conducted properly, inconsistencies will disappear as the individual concerns begin to overlap and compliment each other; patterns will emerge and concerns will be strengthened.

- $\quad$ Exit Meeting

At the conclusion of the assessment, an exit meeting should be held with the entire assessment team and appropriate management and personnel. During the exit meeting the team members will discuss the strengths they have observed, the concerns that they have, the weaknesses they perceive, and any recommendations they deem appropriate. The exit meeting should be a formal presentation of the information that has been provided to facility management throughout the assessment (i.e., no surprises).

\section{A.3.7 Assessment Documentation}

Team members should document their reviews, interviews, and observations. It is generally best if team members compile their notes and write up their assessment activities on a daily basis. The success of the assessment is highly dependent upon the level of documentation available to substantiate the issues. One approach is for the write-ups to be in the form of strengths, concerns, and potential problems.

A strength is a program or activity that is considered effective and exceeds the expectation outlined in the assessment criteria. A strength will be performance-based and must be supported by clear observable evidence (e.g., a great program on paper but not implemented will not be a strength).

A concern is a weakness in a program or activity that has resulted in identified problems or is deemed to not satisfy the intent of the assessment criteria. For each concern, a recommendation for corrective action(s) or improvement should be provided. 
A potential problem is a perceived weakness in a program or activity based on the experience of the team members which is not deemed to be performance-based but may lead to future problems if left unaddressed (i.e., programmatic).

\section{A.3.8 Assessment Report}

Final documentation of the assessment should typically take the form of a written report. Comprehensive and complete write-ups during the assessment will expedite and enhance the written report. The report should be reviewed in draft by the appropriate facility managers. When a mutual understanding of the issues and recommendations is reached and comments incorporated, the report will be issued as final for action.

\section{A.4 ASSESSMENT TECHNIQUES}

\section{A.4.1 Interviews}

Interviews are the most visible element of an assessment. They can be both time consuming and a time saver, depending on how effectively they are conducted. They can set the tone for the assessment and, if properly conducted, will leave the impression of a professional job well done. They can also be misleading and inexact because information gathered in this manner is often based on "perceptions" and not fact. The following principles are provided for making the most of the interviewing process:

- Planning is important and should always precede $\epsilon_{\text {c.ch }}$ interview. Make an appointment whenever possible to prevent false starts and to minimize the impact on the time of the facility personnel. Always work to their schedule and if an emergency arises during the interview, reschedule the interview for another time. If possible, call ahead to inform the interviewee of the subject to be discussed to allow preparation prior to the interview. Provide the interviewee with any documented material felt to be of interest (e.g., a copy of the assessment criteria). This will save time and help establish an air of candor and openness.

- Establish an interview schedule that allows the collection of information from various levels in the hierarchy. For example, plan to interview the manager, supervisors, and several people at the working level. Confining the interviews to just the top or bottom can give a distorted or biased view of the problems. Frequently, the view of how the organization operates and the problems perceived by management is not supported by interviews conducted lower in the organization; this difference is itself a problem (i.e., an indication of communication or management inattention to problems).

- There are basically two types of questions: open questions and closed question. An open question is one which can not be addressed with a simple yes or no answer; it is intended to gather a large amount of information from the interviewee (e.g., "How does your design process work?"). A closed question can be answered with a simple yes or no and is intended to clarify a point or confirm your understanding of a fact (e.g., "Do you require conceptual design walkdowns?"). 
Rely heavily on open questions, especially early in the interviewing process, to gain an understanding of current programs, processes, or practices and their resultant problems. Open questions appropriately shift most of the talking to the interviewee and reduces the feeling of an interrogation. Toward the end of the interview, sparingly use closed questions to solidify an understanding of the facts.

- Develop a list of questions, in advance, and use them as a guide. The questions should be a result of prework, i.e., document reviews, observations, and previous interviews. Feel free to deviate from these questions if the subject warrants, but do not leave the interview unless the questions on the list have been covered.

- Keep good notes; if memory is relied on, important details and facts may be forgotten after a short time. Inform the interviewee that any notes taken during the interview will be kept confidential.

- Interviews can provide a quick understanding of the policies and practices in place at the time of the assessment. However, remember that they are typically the "perceptions" of the interviewee and are not necessarily a statement of fact. If the interviewee states that problems exist, ask for examples and check them out later. This is especially important in a performance-based assessment.,

- Try to identify the root-cause and total impact of an identified problem before going on to the next issue. If experience and instincts lead to a belief that a major problem may exist, do not stop just because the facility may have already investigated the problem and concluded that a concern does not exist. The technique is referred to as a "pulling the string". For example, if told that the diesel generator room automatic ventilation dampers are wired closed, and the interviewee has concluded that this does not pose a problem because the diesel generators are water cooled, investigate further. Ask the question "Why were the dampers designed to be automatic and what were they designed to protect?". The answer in this case is "to cool everything in the room", not just the diesel generators. The problem becomes the concern over the environmental qualification of control panels and electrical components in the room (which are not cooled by any other means). This example came from a previous assessment and resulted in a reportable event because the problem went undetected until the evaluator "pulled the string".

- Allow at least a half hour between each interview. This time should be used in case of overrun or to collect thoughts and finish notes before the next interview starts.

\section{A.4.2 Document Reviews}

The number of available documents associated with a typical facility can be overwhelming. The evaluator should review whatever documents may be relevant; including documents listen in table C-1 (as they apply to the situation). As a minimum, the Requirements Source documents listed in the table should be given careful attention. 


\section{A.4.3 Observations}

Observations are an excellent method for gathering facts to support performance-based recommendations. Typically, the evaluator will assure a nonparticipative role in order to assure that the activity under observation is not changed by the intervention of the evaluator (i.e., do not affect the "normal" way of doing things). Keep detailed notes indicating the type of activity, objectives, time participants, and results. In order to maintain confidentiality, avoid use of names in the final report; it is acceptable to refer to titles if this does not directly refer to an individual. The following activities lend themselves to observations:

- Work in Progress (e.g., overhauling a pump),

- Meetings (e.g., problem solving, information), and

- General Facility Conditions (e.g., material conditions, housekeeping, as-built conditions). 


\section{Appendix B}

\section{CHANGE CONTROL PROCESS}

Change control is essential to maintaining an important configuration once it has been established. The general change control process outlined below. It can be adapted to various forms of change, from physical modifications to alterations in how activities are conducted. This model should be used as a basis of comparison with existing or planned change control processes: any process should have the basic elements described.

Change control should be described in approved procedures. For each potential type of change, procedures should include the following steps: proposal, evaluation and acceptance, development, review, approval, implementation, field changes, validation, operation, and documentation. Relationships between these steps are shown in Figure B-1 and summarized below.

For many types of changes, a change control form such as shown in Figure B-2 may be useful. This example is based on forms used in Energy Systems and other companies. It provides a convenient way to ensure proper steps are taken, decisions are recorded, and the status of the change is known. It may be adopted and adapted as needed.

\section{B.1 PROPOSAL}

The proposal should describe the change, benefits of the change, why it is needed, and how it would be implemented. The proposal should estimate potential impacts of the change on design requirements, operating procedures, instrument set-points, equipment alignment, and sequence of operations. The proposal should describe use of existing components and procedures (including software); necessary modifications to existing components and procedures; the need to design, procure, and install new components; and "like-kind" replacement of components. The proposal should also indicate whether items involved in a change are important to health, safety or environmental protection.

\section{B.2 ACCEPTANCE}

The proposal assists in determining whether a change is acceptable before resources are invested in developing details of the change. Acceptance means a decision is made to continue developing the change based on evaluation of projected costs, need, benefits, and estimated impacts of the change on health, safety, environment, and other concerns. The responsible manager or a designated representative accepts the proposal. Acceptance or rejection of a proposed change and the basis for the decision should be documented. 
Figure B-1

Change Control Process

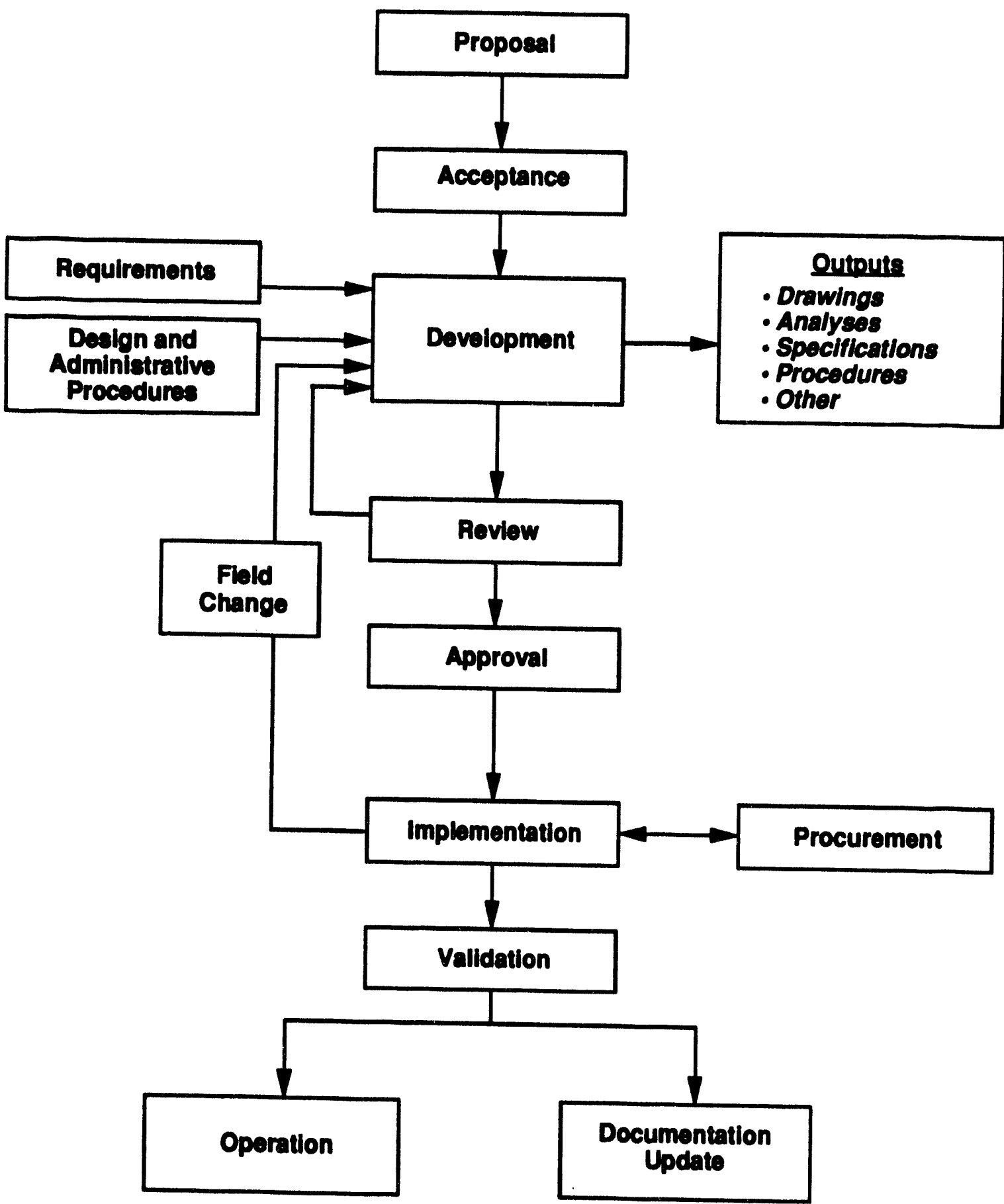


Figure B-2

Change Control Form

PROPOSAL

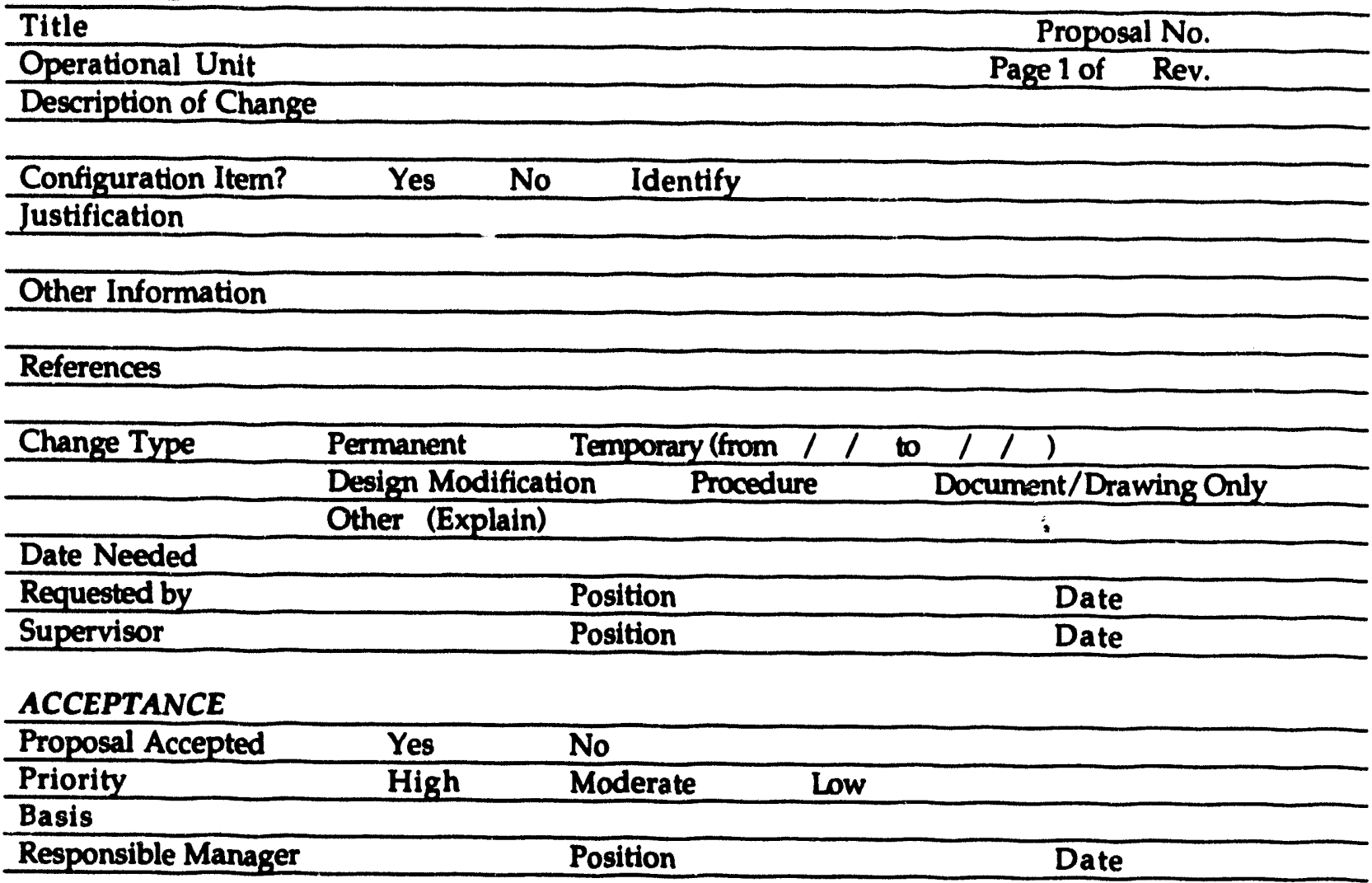

REVIEW

[Attach design or document change package.]

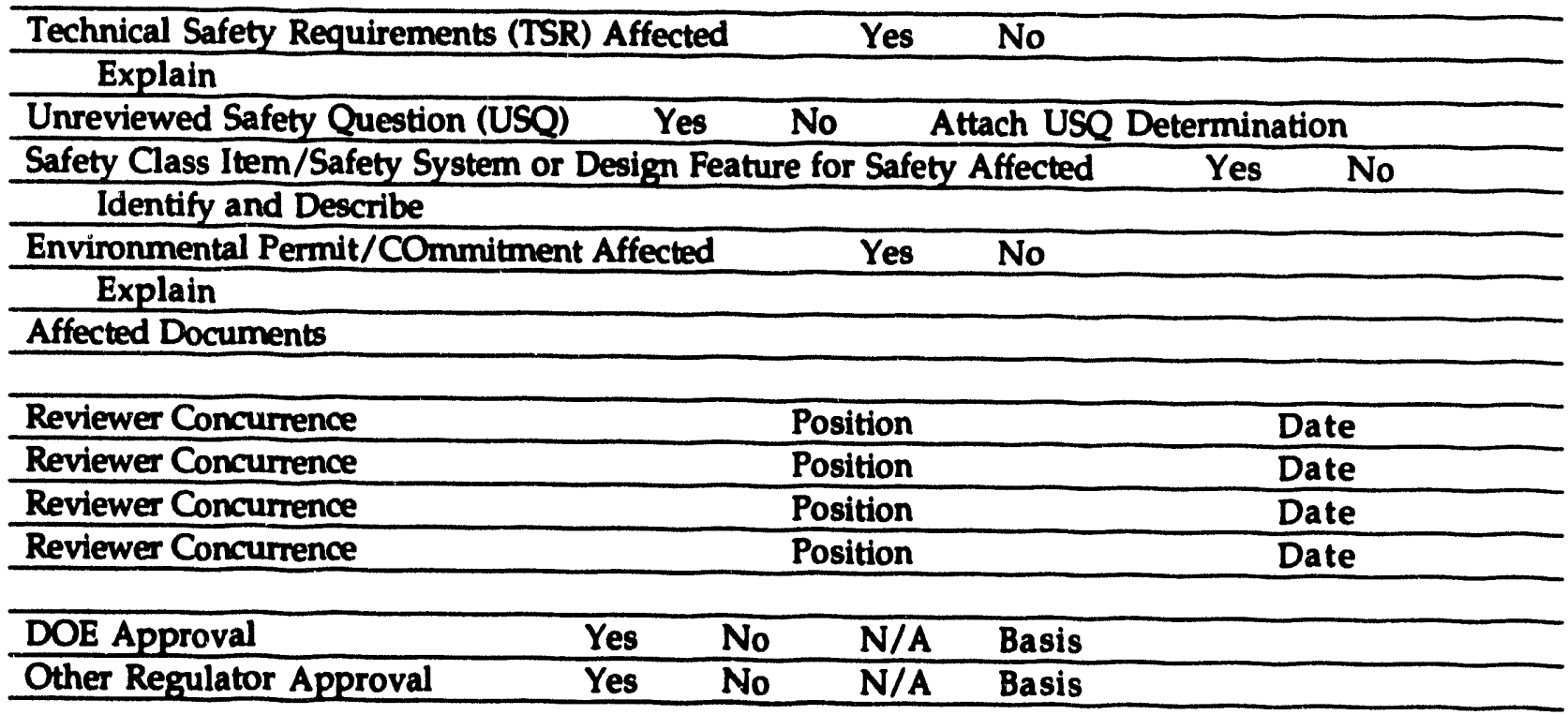


Figure B-2

Change Control Form (continued)

\begin{tabular}{|c|c|c|c|c|}
\hline Approval to Implement & & Position & Date & \\
\hline \multicolumn{5}{|l|}{ CLOSEOUT } \\
\hline Title & & & \multicolumn{2}{|l|}{ Proposal No. } \\
\hline Operating Unit & & & Page 2 of & \\
\hline \multicolumn{5}{|l|}{ Description of Change } \\
\hline \multicolumn{5}{|l|}{ Work Packages Complete No. } \\
\hline Verified & & Position & Date & \\
\hline \multicolumn{5}{|l|}{ Documents Updated: } \\
\hline Verified & & Position & Date & \\
\hline Drawings & No. & Title & Rev. & (list all) \\
\hline Procedures & No. & Title & Rev. & (list all) \\
\hline Technical Safety Requirement(TSR) & No. & Title & Rev. & (list all) \\
\hline Safety Analysis: Document Name & No. & Section & Rev. & (list all) \\
\hline Vendor Manuals & No. & Title & Rev. & (list all) \\
\hline Specifications & No. & Title & Rev. & (list all) \\
\hline Other Documents/Records & No. & Title & Rev. & (list all) \\
\hline Training Updated & & Training Complete & & \\
\hline Verified & & Position & Date & \\
\hline Validation Complete & & Procedure & & \\
\hline Verified & & Position & Date & \\
\hline Approved for Operation & & Position & Date & \\
\hline
\end{tabular}




\section{B.3 DEVELOPMENT}

Details of a change are developed by establishing bases, selecting and applying analytical models, making simplifying assumptions, performing calculations and studies, and selecting the most desirable design or approach by considering viable alternatives. For example, the safety analysis report is the basis for safety requirements, and it should provide essential information for development of changes to safety class items, safety systems and design features for safety. Decisions and conclusions of the development process should be recorded in documents such as drawings, procedures, or safety analysis revisions which can be used to implement the change.

The effort invested in change development should be graded according to the complexity and importance of the item being changed. Change development for the configuration items most important to health, safety, and the environment ( $\mathrm{SCI} 1$ and 2, safety systems and design features for safety, and the key environmental permit items addressed in reference 3) generally should follow approved procedures. It will involve an Unreviewed Safety Question Determination or a review and approval as prescribed in the environmental permil. It often may require fairly sophisticated design or analytical methods such as probabilistic risk assessments. Occasionally, recovery or ( $\mathrm{r}$ - rely) re-creation of missing information may be needed to support decisions.

On the other hand, change development for the somewhat less important configuration items added in Phase II (e.g., SCI 3, remaining environmental protection items, and selected safeguards and security or emergency plan items) will generally require less demanding practices. Changes to these items may be screened out of the Unreviewed Safety Question Determination and environmental permit processes. They should also require less sophisticated design and analytical methods: For example, a back of the envelope calculation will often suffice. Recovery or re-creation of missing information should not be needed.

During change development, errors might be found in existing design or administrative requirements. These might be caused by prior misinterpretation of the bases for the requirement or from analytical errors during original design or procedure preparation. If such errors are found,they should be handled like the operational unit handles other weaknesses.

\section{B.4 REVIEW}

Results of change development are reviewed before implementation (a) to avoid overlooking important technical, safety, or environmental issues; (b) to ensure technical correctness of the change development; (c) to properly address potential impacts on adjacent or related facilities, activities, processes, and experiments; and (d) to ensure that implementation of the change, as developed, is feasible and will accomplish the intended purpose without unforeseen consequences. The scope of change review should include the bases, methods, assumptions, conditions, analyses, and evaluations performed in change development. Review comments and resolution of review comments should be documented. Table B-1 provides an example checklist for review. 
Table B-1

EXAMPLE REVIEW CHECKLIST

\begin{tabular}{|c|c|c|}
\hline • & Input & $\begin{array}{l}\text { Are known requirements identified and addressed? } \\
\text { Consider safety analyses, environmental laws/permits, company standards, DOE } \\
\text { standards, laws, regulations, interfacing systems, and customer specifications }\end{array}$ \\
\hline • & $\begin{array}{l}\text { Interfa } \\
\text { - } \\
\text { - } \\
\\
\text { - }\end{array}$ & $\begin{array}{l}\text { Have physical and functional interfaces been identified and addressed? } \\
\text { Have interactions with other systems/activities been identified and addressed? } \\
\text { Have affected documents been identified and revisions initiated? } \\
\text { Consider operations, maintenance, and test and inspection procedures; engineering } \\
\text { drawings; specifications; data sheets and check lists; training materials; and system } \\
\text { descriptions } \\
\text { Has an Unreviewed Safety Question Determination been completed? } \\
\text { Are all affected organizations in the review process? } \\
\text { Consider operations, maintenance, training, test and inspection, engineering, } \\
\text { security, fire protection, health physics, industrial hygiene, indistrial safety, quality, } \\
\text { facility safety, environmental management and/or others as appropriate }\end{array}$ \\
\hline • & $\begin{array}{l}\text { Techni } \\
\bullet \\
\bullet \\
\bullet\end{array}$ & $\begin{array}{l}\text { Are assumptions valid and justified? } \\
\text { Are all credible conditions considered? } \\
\text { Is the design/procedure technically correct and appropriate? } \\
\text { Consider materials, calculations, dimensions, sequence of steps, human factors, } \\
\text { maintainability, environmental qualification, fire hazard, and other factors } \\
\text { addressing the known requirements } \\
\text { Is the design/procedure clear? } \\
\text { Can the design/procedure be implemented reasonably? } \\
\text { Consider accessibility, safety and health, environmental restraints, security, impact } \\
\text { on operations, and time constraints } \\
\text { Is a reasonable and effective validation (test, inspection, or other verification) } \\
\text { process provided? }\end{array}$ \\
\hline
\end{tabular}

To provide an objective review, the review team should include persons who were not involved in the change development. If the change impacts configuration item design or function, the design authority should participate in the review. Other organizations involved in the review should be selected by the responsible manager based on the nature of the change. Organizations which might be considered for participation in reviews include operations, safety analysis, criticality safety, radiation safety, environmental protection, fire protection, industrial safety, industrial hygiene, systems engineering, 
security, procurement, maintenance and construction. These organizations should be included in reviewing changes based on a need for their expertise or because interfaces could impact areas for which they are responsible. In practice a semi-permanent Change Control Board (CCB) for the operational unit is often used to perform or guide the review.

\section{B.5 APPROVAL}

Prior to implementation, the responsible manager should approve configuration item changes. Approval means that the change development and review are acceptable and that the manager accepts responsibility for effects of the change when implemented as approved.

Changes requiring revisions to design requirements should also have concurrence by the design authority. Concurrence means the design authority agrees the change is acceptable and compatible with known design requirements and bases. Change approvals should be documented to provide a record which identifies and describes the change which is approved along with the basis for approval.

Changes to configuration items requiring Unreviewed Safety Question Determinations (USQDs) should not be implemented until the USQD is approved. If the USQD determines that an unreviewed safety question exists, the change may not proceed until DOE or its designee concurs.

\section{B.6 IMPLEMENTATION}

Implementation of a design change involves the procurement and construction activities required to accomplish the approved change. Implementation of an administrative change may involve revisions to procedures, preparation of new procedures, or preparation of training materials for operators. During implementation, inspections and quality control and surveillance activities should be performed to ensure that field modifications, procurement, procedure revisions, or preparation of training materials are performed in accordance with requirements in the approved change. If implementation of the approved change is found to be infeasible or impracticable, it is necessary to prepare a field change describing the alternative accomplishment of the change. Field changes should be identified, developed, documented, reviewed and approved using a process similar to that for the original change.

\section{B.7 VALIDATION}

The implemented change should be inspected and tested to ensure the resulting physical form and functional characteristics are consistent with approved requirements. For design changes this means system components may be operated in a start-up mode, leak tests may be performed, and other nondestructive tests may be performed as required. For administrative changes, re-trained operators should walk through revised procedures under supervision of persons familiar with requirements in the approved change. The purpose of validation is to ensure successful implementation of the approved change and that the system is ready for operation. Performance of validation activities should be documented. 


\section{B.8 OPERATION}

After validation is complete, operation of the modified system or use of revised procedures may commence. Performance should be monitored during in tial operation of a modified system or use of revised procedures to ensure there are no consequences except those anticipated by the change. If unexpected consequences appear, management should quickly take actions to ensure safe conditions and focus on understanding what is happening. Unexpected consequences and their resolution should be documented.

\section{B.9 DOCUMENTATION}

Change control is completed by making a final check of configuration item documentation for completeness and accuracy. Documents should be revised as necessary to incorporate changes to physical form and functional characteristics, procedures, training, and qualification requirements or certification of personnel. 
Appendix C

\section{DOCUMENT CONTROL PROCESS}

The two key parts of adequate document control are the identification of which documents are important, and the placement of these into a satisfactory control system. The following guidelines may be useful in identifying documents that should be controlled, and in either evaluating an existing document control process or setting up a new one. These guidelines are set up around Energy Systems Procedure IO-201, "Document Control" (ref. 4).

\section{C.1 IDENTIFYING DOCUMENTS TO BE CONTROLLED}

A controlled document is any document for which distribution and status are to be kept current by the issuer to ensure that users have accurate information.

Table C-1 suggests example documents that should be considered for control. It should be expanded on or reduced as appropriate. However, some documents must be controlled for any operational unit to wh:ch they apply: These are the "source" documents in the table. These must be controlled because they provide the safety and environmental bases of operation.

The list of other documents to be controlled will depend on the relative importance of the configuration item (e.g., SCI 1 vs. SCI 3), its complexity (e.g., glovebox vs. low level radioactive waste system), and its nature (e.g., activity vs. piping system). For illustration Table C-1 marks with ** examples that might be considered priority for SCI 1 or 2 and most important environmental items (e.g., the configuration items addressed in Phase I), and with * those items that might be considered priority for items that are $\mathrm{SCI} 3$, safeguards and security, other environmental item, or emergency plan. Note that many of these are already controlled in most operational units.

\section{C.2 CONTROLLING/TRACKING CONTROLLED DOCUMENTS}

Once the important configuration item documents have been identified, they must be controlled to the degree necessary to keep them accurate and current. A successful document control process is one that ensures anyone making an important decision--from a health, safety, and environmental viewpoint-has an accurate document.

The document control process can be sophisticated or simple, depending on the operation unit's needs. In either case, or between, a successful process will have the following characteristics:

- It is clearly documented in procedures and communicated to personnel to ensure it is followed consistently and completely. 
Table C-1

\section{CANDIDATE DOCUMENTS FOR CONTROL IN PHASE II}

\begin{tabular}{|c|c|}
\hline DOCUMENTS & EXAMPLES \\
\hline $\begin{array}{l}\text { Requirements Source } \\
\text { Safety: } \mathrm{SCl} 1,2,3 \\
\text { Safety Systems } \\
\text { Design Features for } \\
\text { Safety } \\
\\
\text { Environmental }\end{array}$ & 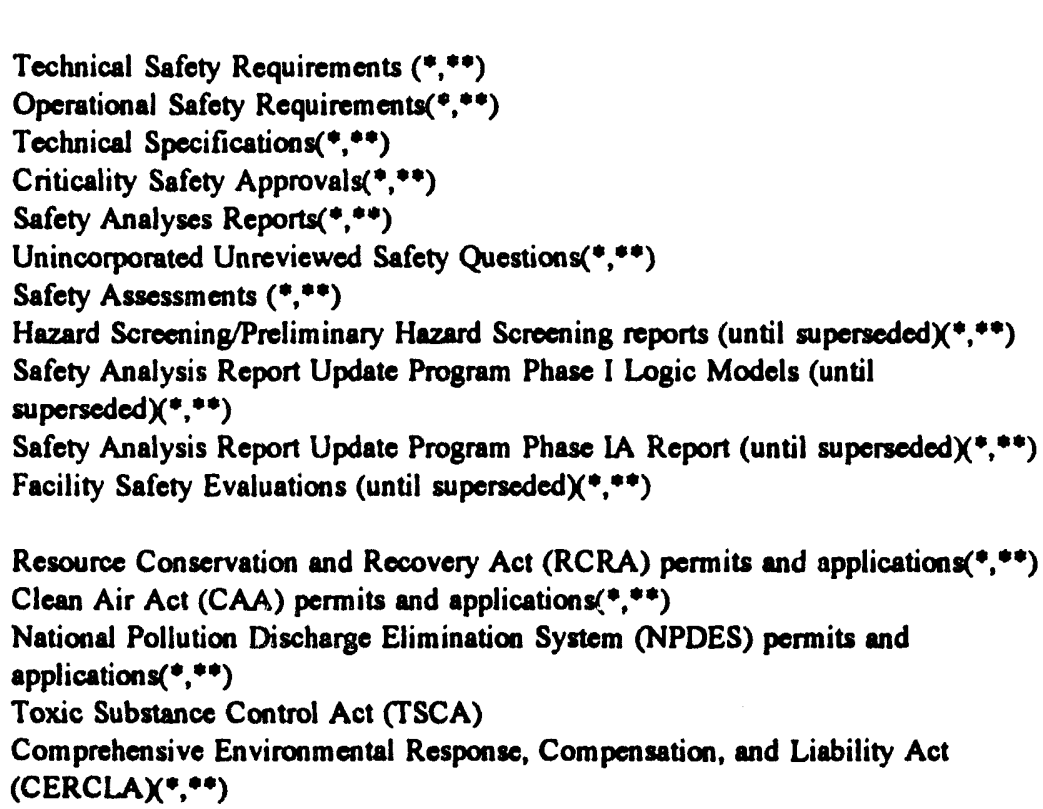 \\
\hline $\begin{array}{l}\text { Supporting (contain details } \\
\text { supporting the source } \\
\text { documents) }\end{array}$ & 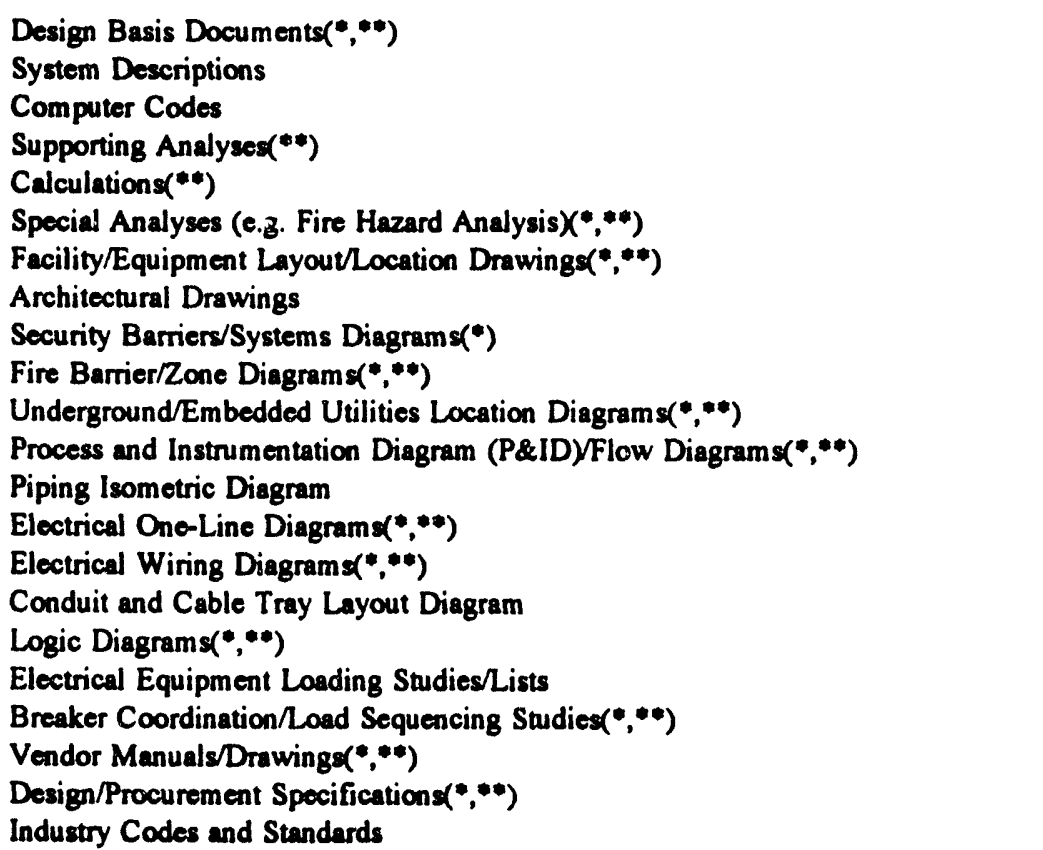 \\
\hline
\end{tabular}


Table C-1 (continued)

\section{CANDIDATE DOCUMENTS FOR CONTROL IN PHASE II}

\begin{tabular}{|c|c|}
\hline $\begin{array}{l}\text { Controlling (control activities } \\
\text { for making changes) }\end{array}$ & 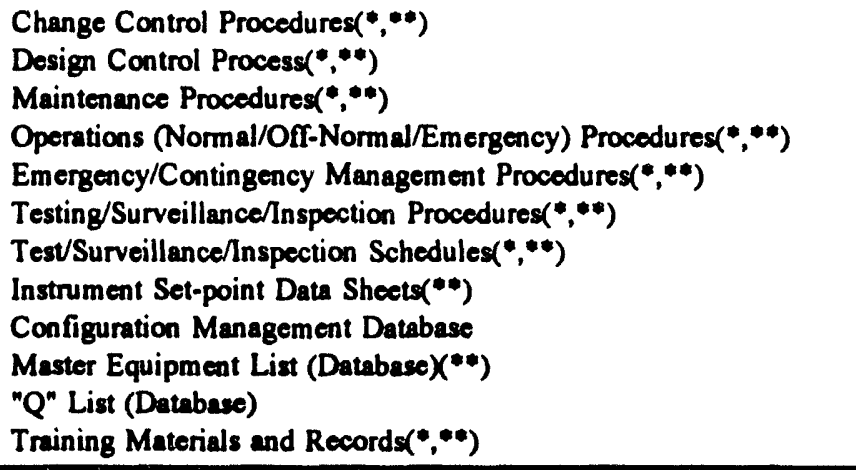 \\
\hline $\begin{array}{l}\text { Additional Records (record } \\
\text { changes and events used as } \\
\text { basis for change decision) }\end{array}$ & $\begin{array}{l}\text { Data Sheets/Report } \\
\text { Operations Logs(",**) } \\
\text { Maintenance Records } \\
\text { Test/Surveillance/lnspection Records(*,**) } \\
\text { Equipment Performance/Trend Studies } \\
\text { Discrepancy Reports (e.g., Non-Conformance Reports) } \\
\text { Unreviewed Safety Question Determinations(*,**) } \\
\text { Change Control Board Minutes(*,*") } \\
\text { Change Control Packages(***) } \\
\text { Procurement Records(",**) } \\
\text { Training and Qualification Records (e.g., Welder qualification)(**) }\end{array}$ \\
\hline
\end{tabular}

- It prevents use of superseded or uncontrolled documents for change control decisions. Operating, design, maintenance, and other activities should require use of only the latest revision of controlled documents for decisions affecting health, safety, and the environment. Uncontrolled documents often have unapproved changes, such as annotations, that can lead to inappropriate actions. (If the annotations are correct and useful, the controlled document should be revised to incorporate them.).

- It clearly defines responsibility (i.e., an owner) for each document type. The owner is responsible for the technical content.

- It clearly identifies documents and records to be controlled. These should be the minimum set of documents required to support the approved change control process.

- It ensures that approved document changes are clear, legible, and correct. Review of the changes by knowledgeable people, such as the lead person responsible for developing a change to the configuration item, is generally a good way to ensure the document conveys the intended information.

\footnotetext{
- Items that might be considered priority for items that are SCI 3, safeguards and security, other environmer: : item, or emergency plan

- Examples that might be considered priority for SCI 1 or 2, selected safety systems and design features for safety, and most important environmental items (e.g., the configuration items addressed in Phase D)
} 
- It ensures that approved document changes are prioritized and made promptly such that a backlog does not develop. It specifies the number of unincorporated changes allowed before revision for each document type. Delayed changes can lead to conflicts between documents or between documents and the actual physical/functional configuration. They can also delay operations and development of approved changes, tempting people to circumvent the change control process.

- It safely stores masters of documents to prevent loss, damage, or unauthorized revision. Alternately, multiple controlled sets may be maintained in separate locations, with strict controls to ensure the sets remain identical. It defines required retention times for each document type.

- It makes controlled documents readily available to potential users. Maximum retrieval times are established for each document type. This may require a 24 hour-a-day service for a few operations to avoid significant work delays or use of uncontrolled information. Locally available document control stations may be required in some areas.

- It establishes a distribution list and tracks distribution to ensure users have updated information when changes are made. Distribution of controlled documents may be supplemented by "information only" copies or "temporarily controlled" copies with clearlymarked expiration dates.

- It is tightly tied to the change control process such that a change is not placed into operation without revision of key configuration item documentation.

Consolidating a master copy of all Phase I configuration item documents into a single location can be useful. Consolidated materials may be easier to maintain and easier for users to locate. A central location can also serve as a nucleus for additional materials that are likely to be identified later.

A document database should be considered to assist in tracking documents. Information typically in such a database includes:

- $\quad$ document number
- current revision
-
-
- condistribution uniricorporated changes
- cross reference to other documents
-
- storage location


Appendix D

ENERGY SYSTEMS CONFIGURATION MANAGEMENT WORKING GROUP

Lou Amold

Joe Arrowood

Steve Burnette

George Copen

Paul Davis

M. O. Dixon

Royce English

Ron Glass

Tom Gordon

Bill McClain

John Rayside

Tom Reed

Betty Robinette

Ron Sabin

David Starling

Gerald Turk

Bob Ward
Safety and Health Organization

Computing and Telecommunications Services

Research Reactors Division

Portsmouth

Portsmouth

K-25/Environmental Restoration and Waste Management

Paducah

Central Engineering Services

ORNL

Computing and Telecommunications Services

Safety and Health Organization

$\mathrm{Y}-12$

Information Management Services

Safety and Health Organization

Environmental Restoration

Energy Sysiems Protective Services

Business Management and Administration

The group also has a DOE Observer: Wayne Hankins 


\section{Appendix E}

\section{REFERENCES}

1. Energy Systems Policy ES-CM-100, "Configuration Management," December 22, 1992.

2. Energy Systems Standard ESS-CM-101, "Configuration Management," December 22, 1992.

3. "Configuration Management Overview and Phase I Implementation Guidance," CMWG-2/R1, July 1993.

4. Energy Systems Procedure IO-201, "Document Control," June 25, 1993. 


\section{DISTRIBUTION}

D. I. Allen (PORTS)

H. L. Amold, Jr.

J. L. Arrowood

B. G. Ashdown

H. D. Bewley

D. J. Bostock

S. E. Bumette

D. D. Cannon

G. Copen (PORTS)

L. M. Cuddy

G. W. Curtis

P. I. Davis (PORTS)

M. O. Dixon

R. N. English (PGDP)

G. G. Fee

W. E. Fields

J. Flynn

R. K. Genung

R. W. Glass

L. T. Gordon

D. S. Griffith

L. E. Hall

P. E. Hall

J. J. Hummer

M. J. Johnson

M. W. Kohring

C. B. Landguth

R. P. Leinius

J. P. Lewis

S. H. Lowe

F. K. Martin
W. J. McClain

R. Merriman

M. E. Mitchell

M. K. Morrow

F. R. Mynatt

H. A. Nesteruk

S. A. Polston (PGDP)

J. S. Rayside

L. T. Reed

G. D. Robbins

B. K. Robinette

R. D. Sabin

K. W. Sommerfeld

M. I. Sparks

D. A. Starling

J. G. Stewart

J. D. Stout

A. W. Trivelpiece

G. W. Turk

R. F. Ward

Applied Technology Library

Central Research Library

Laboratory Records Department (2)

Laboratory Records-RC

Patent Section

Y-12 Technical Library

Portsmouth-Library \& Distribution Services

Paducah-Library

\section{External Distribution}

G. W. Benedict, DOE-ORO, Oak Ridge, TN

C. M. Parker, DOE-ORO, Oak Ridge, TN

V. W. Hankins, DOE-ORO, Oak Ridge, TN

J. S. Waddle, DOE-ORO, Oak Ridge, TN

Office of Scientific and Technical Information

US-DOE, P. O. Box 62, Oak Ridge, TN 37831 


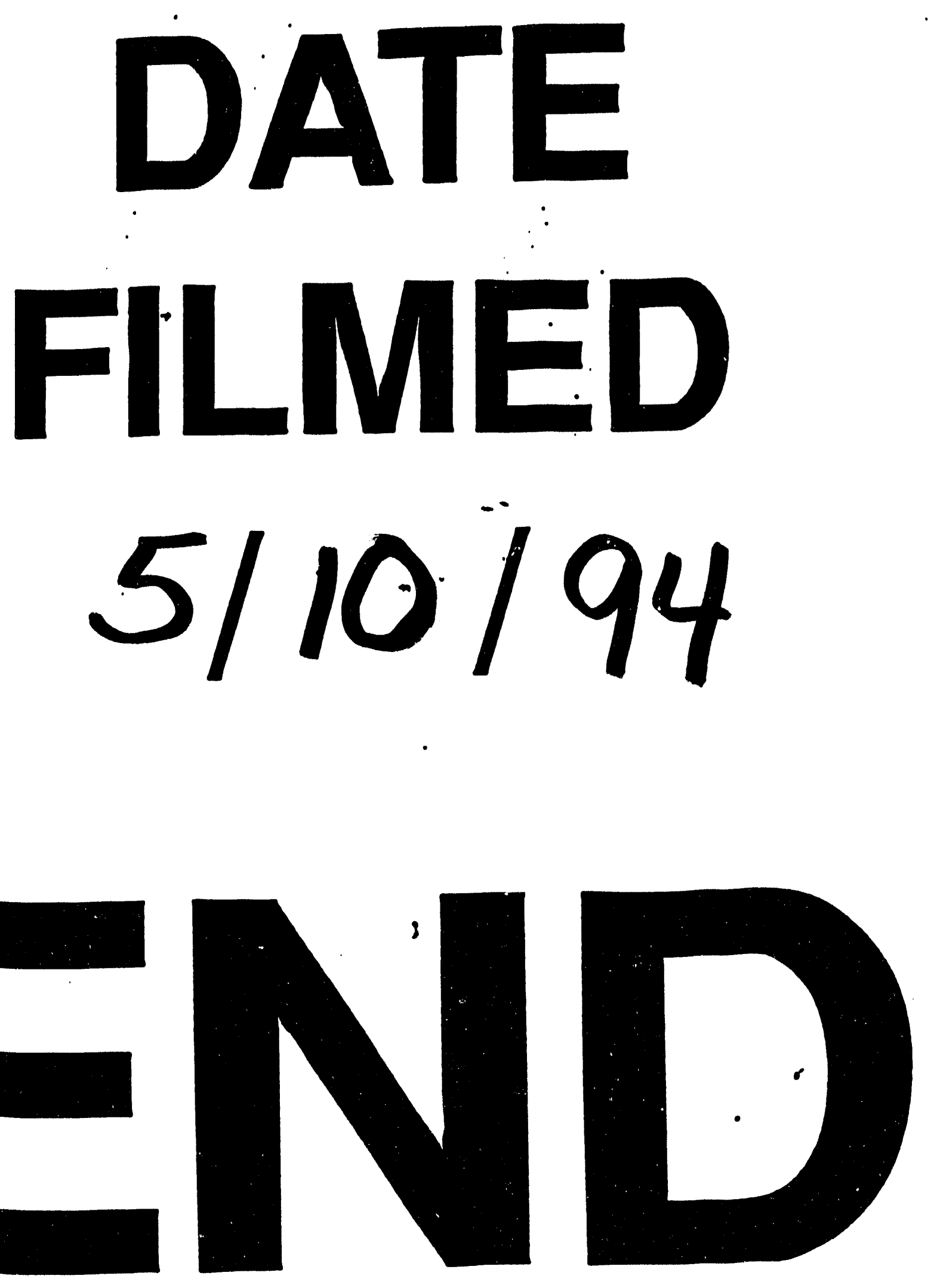


